\title{
DEVELOPMENT AND VALIDATION OF A MEASURE OF WORKPLACE CLIMATE FOR HEALTHY WEIGHT MAINTENANCE
}

\author{
Katherine A. Sliter
}

\author{
A Dissertation \\ Submitted to the Graduate College of Bowling Green \\ State University in partial fulfillment of \\ the requirements for the degree of
}

\section{DOCTOR OF PHILOSOPHY}

August 2012

Committee:

Michael Zickar, Advisor

Vipaporn Phuntumart

Graduate Faculty Representative

Scott Highhouse

Carolyn Tompsett 
This research was partially supported by the National Institute for Occupational Safety and Health Pilot Research Training Program of the Education and Research Center Grant \#T42/OH008432-

06.

(C) 2012

Katherine A. Sliter

All Rights Reserved 


\section{ABSTRACT}

Michael Zickar, Advisor

The obesity epidemic within the United States has resulted in a large and increasing proportion of the American workforce being categorized as overweight. As a result, an increasing amount of research is being conducted to better understand the antecedents and consequences of excess employee weight. One construct often of interest to organizational researchers wishing to understand and influence employee health is organizational climate. Unfortunately, a viable measure of climate as related to employee weight does not currently exist. The purpose of the present study was to remedy this by developing and validating a concise, psychometrically sound measure of climate for healthy weight. A large pool of items was developed based on surveys of full-time employees, and a sorting task was used to eliminate ambiguous items. Next, items were pilot tested by a sample of 338 full-time employees. An initial 3-factor structure was established through exploratory factor analysis, and the set of items was further reduced using reliability analysis and item response theory. Finally, the 14 retained items were completed by a sample of 360 full-time employees, representing 26 different organizations from across the United States. Multilevel modeling indicated that sufficient variance was explained by group membership to conclude that the measure tapping a group-level construct, and confirmatory factor analysis supported the hypothesized model of three subscale factors and an overall climate factor. Validation analyses provided evidence of construct validity. Implications and directions for future research are discussed. 
Dedicated to my parents, Tom and Nancy. 


\section{ACKNOWLEDGMENTS}

First and foremost, I am extremely grateful to my advisor Dr. Michael Zickar for both his insight on this particular project and for all he has done for me throughout my graduate career. Second, I would like to thank the members of my dissertation committee for their helpful contributions throughout the dissertation process. Finally, I would like to thank the University of Cincinnati's Education and Research Center Pilot Research Program, which, in collaboration with the National Institute for Occupational Safety and Health, provided funding for this study. 


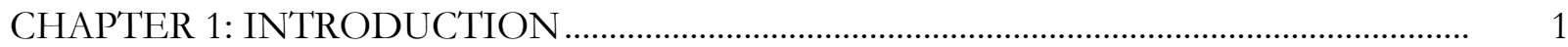

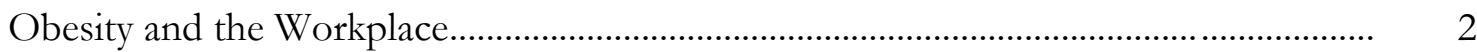

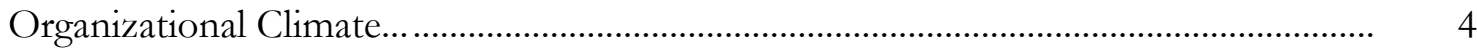

Climate for Healthy Weight ..........................................................................................

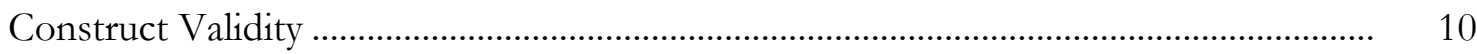

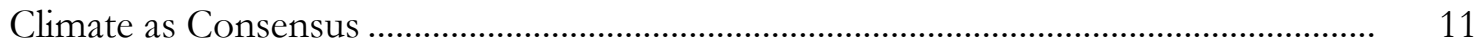

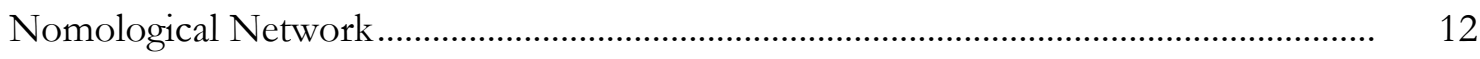

CHAPTER 2: STAGE 1 - ITEM GENERATION …........................................................... 21

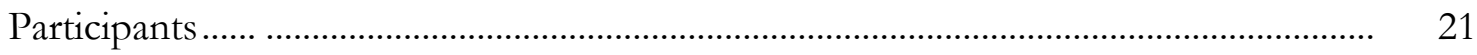

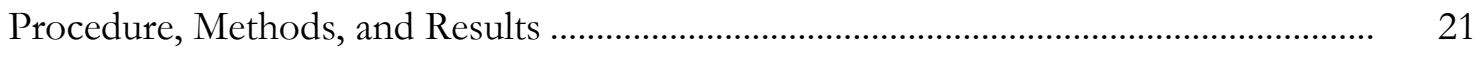

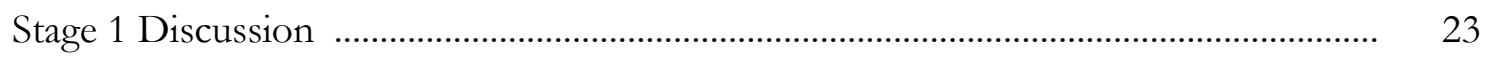

CHAPTER 3: STAGE 2 - PILOT TESTING …................................................................. 25

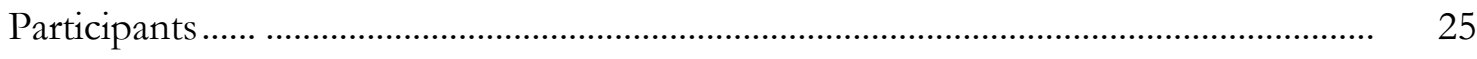

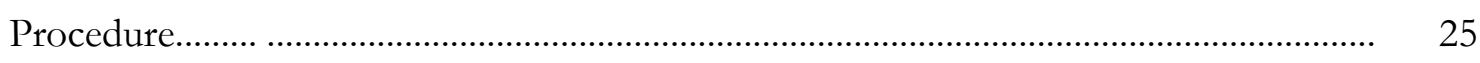

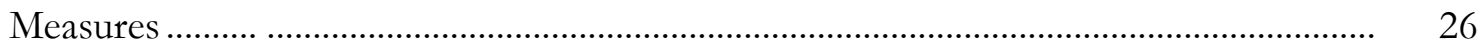

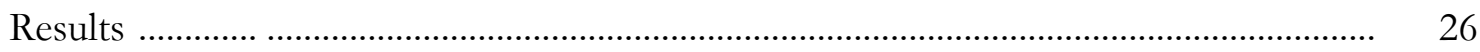

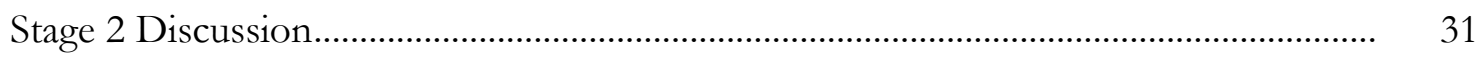

CHAPTER 4: STAGE 3 - APPLIED TESTING AND CONTRUCT VALIDATION ......... 35

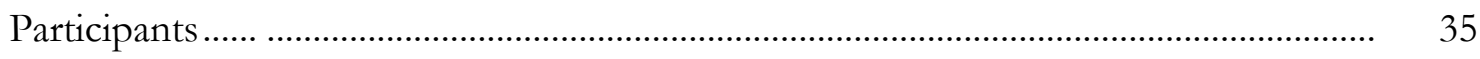

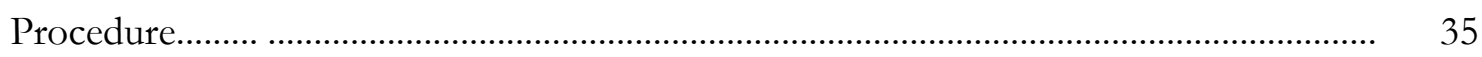

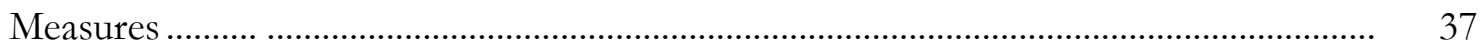

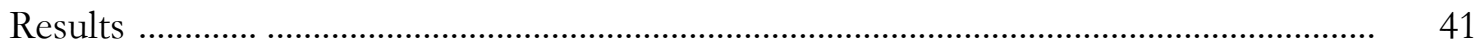




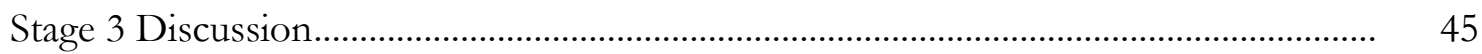

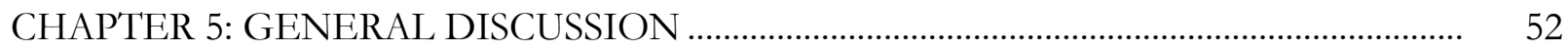

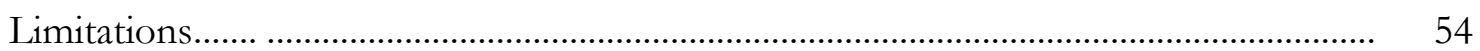

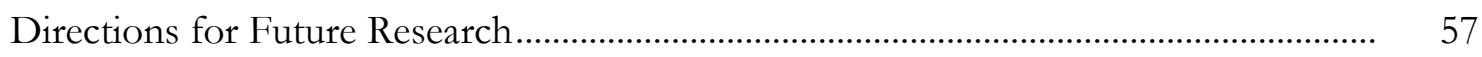

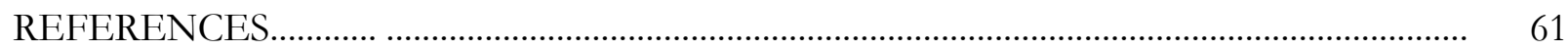

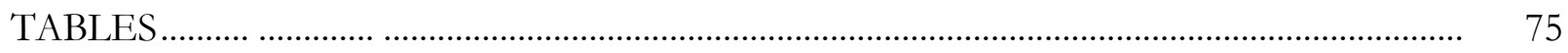

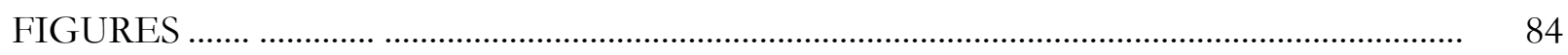

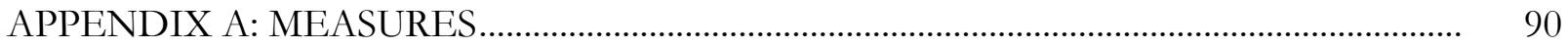

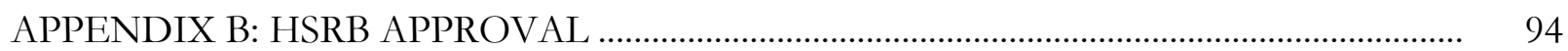




\section{LIST OF TABLES}

Table

Page

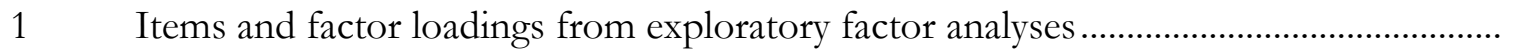

75

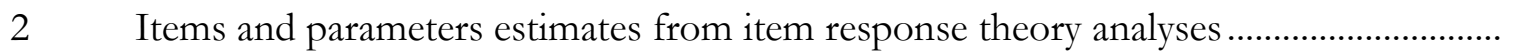

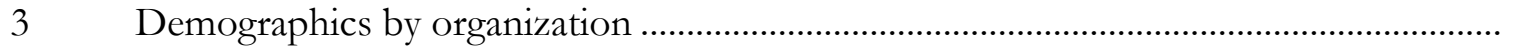

4 Predicted direction and strength of convergent and discriminant validity correlations 81

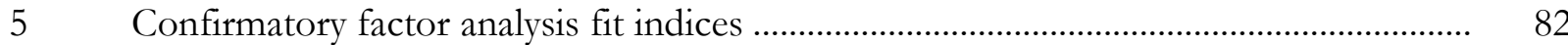

6 Mean item response, standard deviation, and correlations among study variables ......... 


\section{LIST OF FIGURES}

Figure $\quad$ Page

$1 \quad$ Overall test information for organizational support subscale …..................................... 84

$2 \quad$ Overall test information for diet norms subscale ..............................................................

3 Overall test information for social support for healthy weight maintenance subscale86

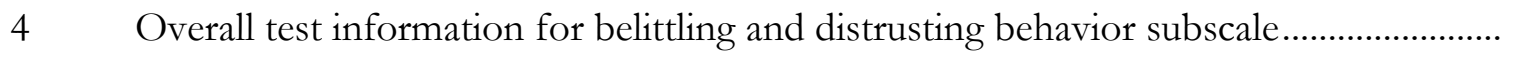

5 Representative item-level information plot for belittling and distrusting behavior

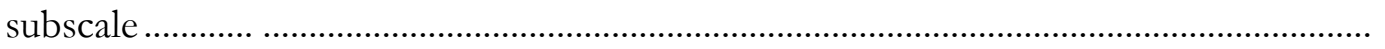

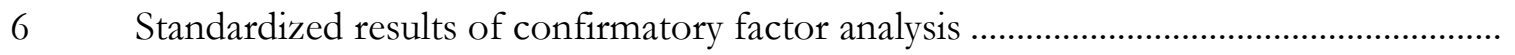




\section{CHAPTER 1: INTRODUCTION}

The United States is experiencing an obesity epidemic, with a large proportion of American workers now overweight or obese (Flegal, Carroll, Ogden, \& Curtin, 2010). Recent estimates shows that over two-thirds of American adults being classifiable as overweight, and half of those, or one quarter of Americans, classifiable as obese (Centers for Disease Control and Prevention, n.d.). This growing demographic within the American workforce has, in turn, resulted in significant negative impacts for the organizations that employ overweight or obese individuals. For example, increased health care costs (Finkelstein, Fiebelkorn, \& Wang, 2003) and lost hours or days of productivity (Ricci \& Chee, 2005) have both been linked to worker obesity, as have more personal outcomes such as greater risk of depressive and anxiety disorders (Scott, McGee, Welles, \& Browne, 2008) and withdrawal behavior (Neovius, Johansson, Kark, \& Neovius, 2008; Ricci \& Chee, 2005). As a result of studies such as these, a growing body of research has emerged with the purpose of understanding the antecedents and consequences of worker overweight/obesity, as well as ways to reduce employee obesity and ameliorate its effects.

For those interested in occupational health topics, a common influence of interest is the climate of an organization. Organizational climate, or employees' shared perceptions of policies, practices, and social norms (Reichers \& Schneider, 1990), is known to impact a broad array of outcomes from performance (Rogg, Schmidt, Shull, \& Schmitt, 2001) to satisfaction (Luthans, Norman, Avolio, \& Avey, 2008). More specific to the aims of the present study, organizational climate is also known to influence health-related behaviors and participation in health interventions or promotion programs developed by organizations (Crump, Earp, Kozma, \& Herz-Picciotto, 1996; Sorensen, Linnan, \& Hunt, 2004). Thus, the examination of climate is considered important for researchers and practitioners interested in understanding and shaping the health-related behaviors of employees. 
Although there is growing interest in researching the effects of obesity and the development of obesity interventions, there currently exists no measure of climate for healthy weight

maintenance. There are a few existing climate measures that assess certain aspects of health, such as safety and general physical health (Basen-Engquist, Hudmon, Tripp, Chamberlain, 1998; Ribisl, K.M., \& Reischl, T.M., 1993) and social support for exercise (Sallis, Grossman, Pinski, Patterson, \& Nader, 1987), but none are designed specifically with weight maintenance in mind. This means that although they may assess certain facets of climate for health weight, important aspects of the construct remain unmeasured.

With this in mind, the goal of the present study was to develop a concise, psychometrically sound measure specifically designed to assess organizational climate for weight maintenance. This was accomplished utilizing a combination of inductive and deductive approaches, with a priori hypotheses created to provide a foundation, and a grounded theory approach used to trim and finalize the scale. First, interviews with incumbents at multiple organizations were used to develop a large pool of indicators of the climate of interest. Once an acceptable pool of indicators was developed, they were administered to a large sample of full-time employees to obtain data for initial analyses. Exploratory factor analysis, item response theory, and other statistical methods were employed to map the factor structure of the measure and to select the smallest possible subset of the indicators for use. Finally, the concise version of the scale, containing 14 items relating to 3 factors, was administered to a sample of full-time adult employees for applied testing. Construct validity of the concise scale was assessed by comparing the organizational climate measure's correlation with several other measures also included in the applied testing phase.

\section{Obesity and the Workplace}

According to the Centers for Disease Control and Prevention (CDC), over two thirds of the American population is overweight, and of these overweight individuals, approximately half can be 
categorized as obese (Flegal, Carroll, Ogden, \& Curtin, 2010). The prevalence of overweight and obesity among Americans has increased steadily for all ages and races of individuals, resulting in an ever larger percentage of overweight and obese individuals both inside and outside of the workforce. Furthermore, this trend is not expected to slow any time soon; a study by Wang, Beydoun, Liang, Caballero, and Kumanyika (2008) projected that the rate of overweight and obesity in the United States population will reach $78.9 \%$ and $49.9 \%$, respectively, by the year 2030 .

The obesity epidemic is not merely a matter of vanity in the workplace. Considerable financial effects on businesses have been, and continue to be, directly associated with unhealthy weight among employees. A comprehensive study by Finkelstein, Fiebelkorn, and Wang (2003), found that between the years of 1996 and 1998, American businesses spent approximately $\$ 52$ billion $(9.1 \%$ of total health care costs) on conditions directly related to employee overweight/obesity. These costs are not expected to lessen any time soon. Finkelsetin, et al. (2003) found that the costs associated with weight were increasing by about $10 \%$ per year and Wang, et. al's (2008) projective study estimated that by 2030, employee health care costs related to overweight/obesity could range between $\$ 860$ and $\$ 956$ billion.

In addition to an inflated financial burden, several other negative workplace outcomes have been linked to overweight/obese status among employees. A study by Østbye, Dement, and Krause (2007), for instance, found a significant linear relationship between weight status and the rate of workers' compensation claims. In their study, workers who were the most obese filed approximately twice as many claims as their healthy-weight counterparts (11.65 claims per 100 individuals versus 5.80, respectively). Obesity was also linked with a large increase in lost days of productivity in this study: the most obese employees averaged 183.63 lost workdays per 100 employees versus 14.19 lost days per 100 healthy-weight employees. Overweight/obesity among employees has also been linked to increased rates of on-the-job injuries (Pollack, Sorock, Slade, Catley, Sircar, Taiwo, et.al. 2007), 
limitations in type/amount of work an employee is able to perform (Hertz, Unger, McDonald, Lustik, \& Biddulph-Kretar, 2004), risk of depressive and anxiety disorders (Scott, McGee, Welles, \& Browne, 2008), and withdrawal behavior (Neovius, Johansson, Kark, \& Neovius, 2008; Ricci \& Chee, 2005).

\section{Organizational Climate}

As can be seen from the studies cited above, the widely publicized state of the American obesity epidemic has spurred interest in the understanding of the effects of excess weight among employees. Despite this growing interest, researchers and practitioners interested in assessing obesity in the workplace still lack the ability to assess a construct often considered of importance in organizational research: climate. Perhaps the earliest known mention of climate, in a social context, occurred in Lewin, Lippitt, and White's (1939) discussion of the effects of various leadership styles on a group of boys at a summer camp. In this article, the term climate was used to describe the shared beliefs, feelings, and social norms associated with the groups. Interestingly, the idea of climate was viewed by the authors as something highly malleable; a change in leadership style, or an actual change in leader, could lead to significant changes in the climate within the group. Although not specific to the workplace, Lewin, Lippit, and White's (1939) manuscript, and the definition of climate contained therein, set the stage for the study of climate in organizations.

Decades later, many subtly different definitions of work-related climate exist, but most, if not all, still revolve around the idea of climate representing a consensus of perception among employees (Denison, 1996). More specifically, organizational climate can be defined as employees’ shared perceptions of the policies and acceptable practices and procedures within an organization, as well as their perceptions of the less formal social aspects of the organization (Reichers \& Schneider, 1990). It is also important to note that the definition of climate has evolved from the idea of a single general climate within an organization to being seen as a more facet-specific construct (Reichers \& 
Schneider, 1990; Schneider, 1975). That is, climate is viewed by many as being a climate for something, meaning that an organization can, and generally will, have multiple climates, each representing employees' shared views centered around a different concept or outcome (Schneider, 1975). As examples, previous research has examined workplace climates for safety (Beus, Payne, Bergman, \& Arthur, 2010; Flin, Burns, Mearns, Yule, \& Robertson, 2006), sexual harassment (Fitzgerald, Drasgow, Hulin, Gelfand, \& Magley, 1997), service (Salanova, Agut, \& Peiro, 2005), and communication (van den Hooff \& de Ridder, 2004; Wynia, Johnson, McCoy, Griffin, \& Osborn, 2010.)

Organizational climate is influenced by informal aspects within an organization, such as its traditions and norms, the characteristics of the people themselves, and so forth, as well as formal aspects of the organization such as official guidelines or rules (Litwin, \& Stringer, 1968; Reichers \& Schneider, 1990). Guion's (1973) meteorological metaphor for climate helps to clarify this interaction: just as wind chill is a perceptual combination of two observables, wind speed and temperature, organizational climate is a perceptual combination of the observable variables of formal policies/procedures and employees' indications of their opinions and beliefs about these formal aspects. By aggregating employees' individual appraisals and perceptions to a higher level, such as that of a workgroup or office, a convergent measure of the interaction of these aspects can be obtained (Kozlowski \& Klein, 2000). This aggregate measure is then termed organizational climate, and it represents employees' consensual interpretations and evaluations of the formal aspects of their work environment and their prescription for behavior based thereon (Zohar, 2003). Thus, studying climate is a way to study the reality of an organization as seen through the eyes of the people within it.

For both researchers and practitioners, the measurement of organizational climates is of interest mainly because of its known influence on employee outcomes. Organizational climate is 
related to many important behaviors and attitudes in the workplace, including job performance (Mercer \& Bilson, 1985; Pritchard \& Karasick, 1971; Rogg, Schmidt, Shull, \& Schmitt, 2001; Yeh, 2009), turnover (Aarons \& Sawitzky, 2006), job satisfaction and commitment (Luthans, Norman, Avolio, \& Avey, 2008; Pritchard \& Karasick, 1971), and unethical or deviant behavior (Robinson \& Bennett, 1995; Peterson, 2002). More specific to the occupational health focus of the present study, part research has shown that organizational climate significantly relates to adoption of anti-smoking policies (Emmons, Thompson, McLerran, Sorensen, Linnan, Basen-Engquist, \& Biener, 2000) as well as participation in workplace programs designed to promote hearth health (Rost, Connell, Schechtman, Barzilai, \& Fisher, 1990), consumption of fruits and vegetables (Sorensen, Linnan, \& Hunt, 2004), smoking cessation (Emont \& Cummings, 1990), and general wellness (Crump, Earp, Kozma, \& Herz-Picciotto, 1996; DeJoy, Bowen, Baker, Bynum, Wilson, Goetzel, \& Dishman, 2009; Sloan \& Gruman, 1988).

Climate is also a useful construct in the study of employee health because it is seen as being relatively malleable. Indeed, in his discussion of the state of the research on organizational climate, Denison (1996) pointed out that climate tends to be viewed as being "relatively temporary [and] subject to direct control” (p.624) by an organization. An organizational climate results from the interaction between the employees and aspects of their environment (Forehand \& Gilmer, 1964; Moran \& Volkwein, 1992) and by directly influencing certain aspects of the environment, an organization has an opportunity to influence the climate. In an early work on organizational climate, Litwin and Stringer (1968) identified some specific influences on the development of a climate, several of which could be directly impacted by an organization desiring change organizational standards, structure, responsibility, and rewards, for example. Climate's element of manipulability, coupled with its relationship with employee behavior and attitudes, make it a desirable construct to consider when seeking to understand an organization. 


\section{Climate for Healthy Weight}

For the growing number of researchers interested in studying the effects of weight in the workplace, being able to measure and account for the related organizational climate would likely be very helpful. Climate is frequently a variable of interest in health-related interventions (Larson, Early, Cloonan, Sugrue, \& Parides, 2000; Smith, Smoll, \& Cumming, 2007), meaning that a measure of weight-related organizational climate would be beneficial for practitioners wishing to improve the health of workers through weight-related interventions. A measure of healthy weight climate would also be a boon for researchers as it would allow for expansion of the theoretical framework surrounding weight in the workplace. The measure would provide a new lens to view the antecedents and consequences of employee weight and this would be a positive step in this relatively young area of research.

The focus of the present study was upon the development of a concise measure for a newly proposed organizational climate, the climate for healthy weight. A measure of this climate would be beneficial for researchers and practitioners interested in understanding the correlates of employee obesity as climate is known to be an influence upon employee behaviors and experiences (e.g. Aarons \& Sawitzky, 2006; Peterson, 2002; Rogg, Schmidt, Shull, \& Schmitt, 2001). In short, healthy weight climate was expected to encompass employees' shared perceptions of the importance that the organization and its individuals place on maintaining a healthy weight. It is worth noting that this climate was not conceptualized as representing any value-laden individual or group-level judgments regarding thinness or adiposity. It was not intended to measure how much employees within an organization like or dislike obese individuals. Rather, it was expected to assess employees' shared perceptions of organizational practices and policies and members' beliefs, attitudes, and behaviors regarding maintenance of weight for the purposes of health, not vanity. 
To adequately assess this proposed construct, it was expected that multiple related but distinct facets would need to be measured. This was determined, in part, based upon previously published measures of various specific climates (e.g. Beus, Payne, Bergman, \& Arthur, 2010; Salanova, Agut, \& Peiro, 2005; Williamson, Feyer, Cairns, \& Biancotti, 1997), all of which included multiple facets to ensure content validity. The assumption of a multifaceted construct was also consistent with the very definition of climate. Although definitions vary, the majority, if not all, make reference to the fact that climate is composed of employees' shared perceptions of multiple aspects of the organization (Denison, 1996; Reichers \& Schneider, 1990; Schneider, 1975; Zohar, 2000). Identifying and assessing the various facets of a specific organizational climate, then, is important as the underlying factor structure is almost certainly multidimensional and should be modeled accordingly.

To establish a priori hypotheses about the facets included in the climate for healthy weight, qualitative data from 151 organizations in Northern Ohio (Employers’ Resource Council, 2010) were examined. This data set included information about organizations ranging in size from only about ten employees to well over five hundred and also represented a broad range of industries, from manufacturing to insurance to post-secondary education. For each organization, two or more employees responded to open-ended questions about things that their organizations, or the people therein, regularly do to encourage or discourage health among employees. Responses that related to weight maintenance were used to develop the following list of proposed facets expected to be part of the measure of climate for healthy weight. Please note that this list was only intended as an initial guide and was expected to change based upon the interviews and analyses performed for the various studies.

Organizational policies and incentives for healthy weight A majority of respondents who indicated that their organizations supported healthy weight also mentioned that their 
organizations had policies and incentives advocating weight maintenance. Examples included allowing the use of flexible spending account funds for weight loss or maintenance programs outside of work (e.g., Weight Watchers), subsidizing all or part of gym memberships, and insurance discounts for employees with body mass index values in the healthy range.

Weight-related information and programs Employees of healthy organizations also frequently indicated that their organizations actively disseminated information to employees about weight maintenance: what to do to maintain a healthy weight, benefits of doing so, and so forth. Most often, this information was passed through relatively simple means such as email "blasts" to employees or posters in the office. A smaller number of employees indicated that their organizations held programs to disseminate the information. Examples included health fairs, presentations, and on-site meetings with a nutritionist or weight counselor.

\section{Leadership support for healthy weight and Coworker support for healthy weight In healthy}

organizations, employees were more likely to identify the managers in their organizations and their coworkers as being supportive of maintaining a health weight. In the case of leadership support for healthy weight, managers were more likely to acknowledge healthy weight-related behaviors among employees, encourage coworkers and subordinates to engage in healthy behaviors at work, and show support for company policies and incentives supporting healthy weight. Examples of coworker support for healthy weight (hypothesized to be a separate facet) included things such as acknowledging healthy weight achievements of fellow employees, offering to carpool to weight maintenance activities (the gym, Weight Watchers meetings), and sharing information and support for weight maintenance. 


\section{Healthy diet norms and Exercise norms Employees of organizations that supported healthy} weight also indicated that their organizations had stronger norms related to eating and exercise. These norms were expressed as tendencies among the employees to be more active and to have a higher quality diet, both inside and outside of the workplace. For instance, several employees indicated that in their offices, employees were more likely to bring low-fat dishes to office get-togethers than to bring cake, cookies, or other sweets. Other examples of diet and exercise norms included things such as being likely to take "active breaks" (e.g., going for a walk after lunch rather than spending time online) and bringing healthy lunches to work rather than eating at a restaurant. Diet norms and exercise norms are hypothesized to be distinct factors from one another but as with leadership and coworker support, they are discussed together for the sake of brevity.

\section{Construct Validity}

Construct validation is the process of establishing a link between a theoretical psychological construct of interest and a specific measurement device or test. For example, a researcher may propose that a new measure assesses self efficacy, a theoretical variable of interest that is not directly observable. Without construct validation, there is no way for the researcher to know whether it actually does, indeed, measure this construct or another. The goal of construct validation, then, is to determine the trait or underlying quality (or set of these) accounting for the variance in scores/outcomes on the measure of interest. Construct validation should be pursued any time that the results of a measure are to be interpreted as an indication of some attribute/quality which can not be directly observed (Cronbach \& Meehl, 1955; DeVellis, 2011).

Construct validity can be broken into two sub-categories, both of which should be pursued in any construct validation process: convergent validity and discriminant validity. Convergent validity is established by showing that the measure being validated is correlated with other established 
measures of constructs with which it should, theoretically, be correlated. Discriminant validity, on the other hand, is established by showing that the measure is not correlated, or weakly correlated, with measures of constructs from which it should be conceptually distinct. For example, if one were developing a measure of workplace aggression, one might expect that the measure should correlate with established measures of general aggression and trait anger but should not correlate as strongly, or in the same direction, with measures of positive affectivity and empathy. This process of testing a measure against its nomological network is long recognized as a good step toward establishing construct validity (Carmines \& Zeller, 1979; Cronbach \& Meehl, 1955).

\section{Climate as Consensus}

A key factor across the various definitions of organizational climate is that the construct represents a shared perception among employees within an organization (Denison, 1996). As pointed out by Glick (1985), it is essential to distinguish between psychological climate, which is unique to the individual and represented by individual-level responses, and organizational climate, which is a consensus of individual opinions. Although climate must initially be assessed at the individual level, because it is a function of individuals' perception of their environment (Verbeke, Volgering, \& Hessels, 1998), the individual-level results need to be aggregated to a higher level to obtain a measure of the collective view of the construct of interest (Kozlowski \& Klein, 2000). Climate is not merely the average response of individuals; rather, climate exists when there is sufficient withingroup consistency in ratings or responses to conclude that respondents are presenting a shared perception of what is being measured.

It is important that the decision to aggregate data to a higher level be supported statistically. There may be conceptual support for the existence of a specific organizational climate, but sufficient agreement among respondents (James, 1982; Glick, 1985) within different organizations is also necessary before the term organizational climate can properly be applied. With this in mind, the 
following hypothesis was tested as a first step toward construct validation, or showing that the measure is assessing the construct it is intended to measure:

H1: Significant within-group agreement, as tested using hierarchical analysis, will be found to statistically support the construct of climate for healthy weight.

\section{Nomological Network}

In the present study, construct validity of the proposed measure of climate for weight maintenance was established by examining its correlations with respondents' scores on several existing measures. The pattern of correlations was used to place the construct of interest, climate for healthy weight, within its nomological network (Carmines \& Zeller, 1979; Cronbach \& Meehl, 1955). Because the proposed scale was intended to measure a new construct, it was important to show that it was conceptually similar to constructs to which it should relate but distinct from those with which it should not be too strongly related. The following list of constructs was examined in relation to climate for weight maintenance in order to establish both discriminant and convergent validity.

Health-Related Behaviors Two behavioral indicators, physical activity and quality of diet, were expected to correlate with organizational climate for health weight maintenance. Previous research on organizational climate has shown that organizational climates tend to be related to behaviors specific to those climates. Neal, Griffin, and Hart (2000), for instance, found significant correlations between safety climate and safety behavior. In this study, perceptions of safety climate were related to both safety compliance $(r=.42)$ and safety participation $(r=.47)$ among employees, results that were similar to those found by Cooper and Phillips (2004) and Zohar (2000). Other examples of specific climates with known links to corresponding behaviors include climate for ethical behavior (Trevino, Butterfield, \& McCabe, 2001), climate for creativity and innovation (Ekvall, 1996), and climate for customer service (Jeff, 1996; Schneider, White, \& Paul, 1998). 
The present study proposed that a climate for weight maintenance exists and that it should be related to behavioral exemplars of weight maintenance. Two behaviors known to relate to weight maintenance are physical activity (Cohen, Gelfand, Dodd, Jensen, \& Turner, 1980; Donnelly, Blair, \& Jakicic, 2009) and the consumption of a healthy diet (Claessens, van Baak, Monsheimer, \& Saris, 2009; Klem, Wing, McGuire, Seagle, \& Hill, 1997). A meta-analysis of 25 years of weight research indicated that both weight loss and weight maintenance, or keeping one's weight at a consistently healthy level, are related to eating healthily and working out, especially when the two are used in conjunction (Miller, Koceja, \& Hamilton, 1997). This is an unsurprising finding given that weight gain is the result of an excess in caloric intake as compared to caloric output. Exercising increases caloric output and a healthy diet reduces caloric intake, meaning that one or a combination of both would help to reduce or eliminate an excess of calories and in turn, stave off weight gain or lead to weight loss.

Given this, it seemed logical to assume that individuals who are part of an organization with a strong climate for healthy weight maintenance would display high levels of both physical activity and diet quality. However, it was not expected that the correlation would be unduly strong, given that factors other than the organization should also influence these behavioral indicators. Examples of such variables are as diverse as spousal support (McLean, Griffin, Toney, \& Hardeman, 2003) and socioeconomic status (Jeffery \& French, 1996). Accordingly, the following construct validation hypotheses were proposed:

H2: Climate for healthy weight will have a moderate positive correlation with self-reported physical activity at the individual level.

H3: Climate for healthy weight will have a moderate positive correlation with self-reported diet quality at the individual level. 
Health Motivation and Knowledge Individuals working within a strong climate for healthy weight maintenance could expected to know more about, and care more about, their health than individuals working within a weaker climate. Climate for healthy weight maintenance should, then, be related to both health motivation and health knowledge. The former of these, health motivation, is a psychological, goal-directed drive to engage in behaviors that encourage maintenance of one's health (MacInnis, Moorman, \& Jaworski, 1991; Moorman \& Matulich, 1993). Health motivation includes both willingness to perform, and interest in, health-related behaviors and has been linked to a greater propensity for engaging in positive health behaviors such as breast selfexamination (Champion, 1988; Fletcher, Morgan, O'Malley, Earp, \& Degnan, 1989), dental care (Davidson \& Andersen, 1997), prenatal care (Zweig, LeFevre, \& Kruse, 1988), joining and sticking with a weight maintenance program (Troumbley \& Lenz, 1992), frequency of fitness center visits (Cobb, Stone, Anonsen, \& Klein, 2000), and consumption of fruits and vegetables (Trudeau, Kristal, Li, \& Patterson, 1998).

Organizational climate is influenced by the beliefs and behaviors of the individuals within the climate (Reichers \& Schneider, 1990), and the healthy weight climate proposed in the present study was hypothesized to involve health-related behaviors and beliefs. Therefore, it would be reasonable to expect that an organization with a strong healthy weight climate would be comprised of individuals with, on average, higher levels of motivation for engaging in healthy behaviors. However, climates are also influenced by the policies and practices of the organization and its leadership, so individual health motivation would be neither the sole determinant nor the only perpetuating factor of a healthy weight climate. Because of this, the following hypothesis was proposed:

H4: Climate for healthy weight will have a moderate positive correlation with health motivation at the individual level. 
Health knowledge, or knowledge of what things influence one's health and how they do so, was expected to have a similar relationship with health weight climate. Like health motivation, a greater level of health knowledge tends to be linked to healthier lifestyle factors. Health-related behaviors such as exercise (Avis, McKinlay, \& Smith, 1990; Howze, Smith, \& DiGilio, 1989; Junqiao, Tanyun, Shoumei, Huifen, \& Hong, 2008), consumption of healthy foods (Boechner, Kohn, \& Rockwell, 1990; Hendrie, Cox, \& Coveney, 2008), seeking treatment for high blood pressure (Speers, Niemcryk, Morter, Gary, \& Ostfeld, 1990), seeking prenatal care (Daniels, Noe, \& Mayberry, 2006), and preventative dental care (Laiho, Honkala, \& Nyyssonen, 1991; Poutanen, Lahti, \& Hausen, 2005), among others, have all been shown to relate to the amount of knowledge that one has about health.

As with health motivation, the directionality of these relationships is unclear- knowledge may cause the behaviors, behaviors may lead to the development of knowledge, or the relationship may be reciprocal. Regardless of directionality, the link between knowledge and behavior was of interest in the present study because if individuals are part of a climate in which health behaviors are more likely, then it would be theoretically reasonable to believe that they would also possess more health knowledge. There should, however, be many other influences on behavior than just knowledge. Individuals in weak healthy weight climates may possess knowledge and not act on it, for instance, whereas those in strong healthy weight climates may engage in health behaviors in order to conform or fit in despite a lack of health knowledge. Due to this reasoning based on past research, the following hypothesis was proposed:

H5: Climate for healthy weight will have a weak positive correlation with health knowledge at the individual level.

It is important to note that the proposed strength of the correlation in the above hypothesis was partially a function of the scale being used to assess the construct. Previous research on health 
knowledge has examined knowledge of health that is specific to the behavioral or psychological outcome of interest. For example, in the previously mentioned studies of the relationship between health knowledge and preventive dental care (Laiho, Honkala, \& Nyyssonen, 1991; Poutanen, Lahti, \& Hausen, 2005), the health measures used were comprised of items targeting specific knowledge of dental health. To the best of the author's knowledge, no scale was presently available which measured health knowledge related specifically to reaching and maintaining a healthy weight. A measure of basic nutrition knowledge (Moorman \& Matulich, 1993) was utilized as a proxy, meaning that certain aspects of knowledge of healthy weight maintenance may have gone untapped. Due to the expected restriction in breadth of the construct to be assessed, only a low correlation was hypothesized between the climate measure and that for health knowledge.

Physiological Variables The healthy weight climate proposed in the present study was assumed to directly relate to individuals' health and health-related behaviors. One way to determine whether the measure is assessing the construct it is assumed to assess is to examine its correlation with physiological indicators of respondents' health. To that end, two physiological measures were gathered for each individual and correlated with the proposed climate for healthy weight: general health symptoms and body mass index.

The first of these, general health symptoms, was used in both a confirmatory and discriminatory manner. Unlike existing measures of health climate (Basen-Engquist, Hudmon, Tripp, Chamberlain, 1998; Ribisl, K.M., \& Reischl, T.M., 1993), the climate for healthy weight scale was not designed to assess a broad range of health-related policies, practices, and beliefs/attitudes. Rather, it was designed to more specifically address employees' shared perceptions of the aspects of their work environment that support or preclude maintenance of a healthy weight. Therefore, it was not expected to correlate too strongly with physiological measures of general health symptoms, as these are likely to be influenced by many other unrelated factors such as family history, stress, past 
experiences or illnesses, and so forth. At the same time, behaviors supportive of healthy weight maintenance, such as aerobic activity, strength training, and consumption of healthier foods should also benefit physical health to at least some extent. Thus, strong climate for healthy weight should have some relationship to general health. With this in mind, the following hypothesis was proposed: H6: Climate for healthy weight will have a weak negative correlation with general health symptoms at the individual level (fewer symptoms should be observed as climate becomes stronger).

Body mass index (BMI), also known as the Quetelet Index, provides an indirect estimate of level of body fatness based on comparative height and weight measurements for an individual. Although BMI is an indirect measure of adiposity, it has been shown to strongly correlate with direct measures of body fat (Garrow \& Webster, 1985), and body fat level, or adiposity, is the very thing around which the proposed climate for healthy weight is hypothesized to revolve. Healthy weight is relative to an individual's height: a weight of 190 pounds can be healthy for a man over six feet tall but would be unhealthy for a woman of average female height. Therefore, BMI, by accounting for both height and weight, provides an excellent physiological measure of healthy weight when direct measures of adiposity are unavailable. As the physical manifestation of the construct of healthy weight, BMI should be more strongly related to the climate for healthy weight than general health symptoms. But just as with general health symptoms, climate is only one of many influences on BMI. With this in mind, the following hypothesis is proposed:

H7: Climate for healthy weight will have a moderate negative correlation with BMI at the individual level.

Characteristics of the Workplace When an organizational climate is being formed or maintained, forces at varying levels of the organization exert influence upon the perceptions that form the climate (Guion, 1973; Litwin \& Stringer, 1968; Reichers \& Schneider, 1990). At the highest 
levels of an organization, formal policies are put forth which outline what is, and is not, allowed within the organization. These policies are then implemented and enforced by managers who have direct contact with the employees whose perceptions form the organizational climate. The formal policies set forth by the organization provide an outline of the goals of the organization and the rewards attached to these goals, whereas the actual practices related to these policies, as shaped by leadership, provide a roadmap for how to attain the goals. (Zohar, 2000; Zohar \& Luria, 2005).

In this multilevel framework of organizational climate, both worksite policies and behavior of the leadership within the organization should influence climate, something which past research has shown to be true. Studies of one of the most commonly studied organizational climates, safety climate, have revealed that companies' formal policies and managers' implementation of these policies are related to perceived safety climate among employees (Pate-Cornell, 1990; Shannon, Mayr, \& Haines, 1997). In organizations with policies making it explicitly clear that safety was desired and rewarded, employees displayed a stronger shared perception of the important of safetyrelated behaviors. When managers indicated support for safety policies, similarly increases in safety climate strength were observed for the employees they supervised. In cases where both company policies and leadership support aligned in a focus on safety, the effect on safety climate was even stronger (Zohar, 2005).

As a result of the past research linking company policies and supervisory support to strong organizational climates, a relationship between these predictors and healthy weight climate was proposed in the present study. In organizations that value and reward healthy weight maintenance, as well as in organizations with leadership that supports health weight maintenance, the employees are likely to have shared perceptions supporting this outcome. In fact, initial hypotheses regarding the factor structure of the proposed measure of climate for healthy weight included both worksite 
incentives for health and leadership support for health as subfacets of the scale. Therefore, the following hypotheses were tested:

H8: Climate for healthy weight will have a moderate positive correlation with organizational support for health at the individual level (level 1) and at the organizational level (level 2). H9: Climate for healthy weight will have a moderate positive correlation with leadership support for health at the individual level (level 1) and at the organizational level (level 2). Existing Health-Related Measures Although there is currently no measure of climate for healthy weight, a few scales exist that measure similar health-related constructs. To establish the proposed climate for healthy weight scale as a valid measure of a unique construct, it was important to examine its relationship to these scales. Two types of existing health scales were examined: scales measuring general health climate (Basen-Engquist, Hudmon, Tripp, Chamberlain, 1998) and scales measuring social support for healthy diet and exercise (Sallis, Grossman, Pinski, Patterson, \& Nader, 1987).

In the case of the general health scale (Basen-Engquist, Hudmon, Tripp, Chamberlain, 1998.), a strong relationship with the climate for healthy weight scale were proposed. The climate for healthy weight measure can be thought of as a more specific, refined type of health climate measure. Whereas the general health climate measure includes a broad range of facets related to health, the proposed measure is targeted specifically toward healthy weight maintenance, incorporating additional facets and removing those inapplicable to weight. Because the proposed climate shares characteristics of the general health climate and is a more tailored version of the larger construct, it was expected that the proposed measure would show significant consistency with the general health climate measure.

However, it was important that the resulting correlations between the new scale and these existing scales not be too high as to indicate redundancy because the proposed measure is intended 
to be more narrowly tailored to the topic of weight. Existing health climate scales contain constructs not theorized as being a part of the proposed healthy weight climate. For instance, the Worksite Health and Safety Climate measure (Basen-Engquist, Hudmon, Tripp, Chamberlain, 1998) assesses supervisor and coworker support for safety behaviors. Therefore, the following hypothesis was proposed

H10: Climate for healthy weight will have a strong positive correlation with the existing health climate measure at the individual level (level 1) and at the organizational level (level 2). Finally, in the case of the scale measuring social support for exercise (Sallis, Grossman, Pinski, Patterson, \& Nader, 1987), a weaker correlation was proposed. This was due to the fact that social support is likely only a subcomponent of climate for healthy weight. The interaction among individuals within an organization does contribute to the formation of specific organizational climates (Reichers \& Schneider, 1990), so it is reasonable to expect that if a group has developed a strong climate for healthy weight, then the individuals within that group would likely be supportive of one another's health-related behaviors. However, climate is influenced by, and includes, other factors such as individual beliefs and attitudes and organizational policies. Thus, the following hypothesis was tested:

H11: Climate for healthy weight will have a moderate positive correlation with the existing measure of social support for exercise at the individual level (level 1) and at the organizational level (level 2). 


\section{CHAPTER 2: STAGE 1 - ITEM GENERATION}

\section{Participants}

Participants in the item generation portion of the study were 46 full-time, non-academic employees from various organizations in two Midwestern states $(n=28)$ and one Southern state $(n=18)$, who had been with their respective organizations a minimum of one year. Of these participants, 11 were known to, but not related to, the author, and the remaining 35 were recruited through referrals given by colleagues of the author or through canvassing of local businesses. Thirty participants were involved in the item generation task and 16 were involved in the subsequent item sorting process.

The participant group for stage 1 contained slightly more males $(n=25,54.35 \%)$ than females $(n=21,45.65 \%)$, had an age range of 21 to 53 years $(M=34, s=5.66)$, and was comprised mostly of non-management employees $(n=44,95.65 \%)$. Participants were primarily Caucasian $(n=37$, $80.43 \%)$, with the remaining individuals self-identifying as African American $(n=6,13.04 \%)$, Asian $(n=2,4.35 \%)$, and Middle Eastern $(n=1,2.18 \%)$. Tenure with present organization ranged from just under 2 years to 22 years $(M=5.22, s=3.08)$. When asked to rate the overall, general healthiness of their organizations, $13(28.26 \%)$ indicated they worked for what they considered to be an unhealthy organization, 16 worked for healthy organizations (34.78\%), and $29(36.96 \%)$ indicated that their organizations fell somewhere in between.

\section{Procedure, Measure, and Results}

Participants for the item generation task were sent an email containing a description of the purpose of the study, an offer of a $\$ 20$ gift card to a major online retailer, and a link to the online interview survey. The survey utilized in the actual item generation process included 13 open-ended questions designed to assess the factors within each individual's organization which both support

and impede healthy weight maintenance. The first twelve questions were designed to gather positive 
and negative statements relating to each of the six hypothesized factors (e.g, "Please tell us about any policies or practices in your organization that help to support maintenance of a healthy weight, and how you feel about them." and "Please tell us about the policies and practices in your organization that get in the way of maintaining a healthy weight, and how you feel about them"). The final question simply asked for any other weight maintenance-related thoughts or experiences that were not covered by the other questions.

Those who elected to follow the link for the survey were first shown an informed consent document and consent for participation was indicated by electronic signature. Participants then completed the online survey by answering the series of questions about their organizations as a whole, the leaders within their organizations, and the people with whom they worked. These questions specifically focused on the weight-related behaviors and practices of each of these three entities, both positive and negative. Upon completion of the study, participants were allowed to enter their contact information in order to receive the offered incentive. Those who wished to maintain anonymity of their responses could elect not to enter their contact information.

The responses to this survey formed the initial item pool, which contained 316 items. The researcher and a trained student assistant examined this list of items and eliminated those that were redundant as well as those that were too vague (e.g., "People here are big"), too specific to an organization or area (e.g., "My company participates in [a popular corporate fitness program specific to one metropolitan area]"), or in some other way unsuited to the purpose of the present study. This resulted in a retained set of 77 unique items that could presumably assess organizational climate for healthy weight. The items were then adjusted to ensure that verb tenses, item stems, and other formatting characteristics were consistent.

This list of items was then sent to the holdout sample of full-time employees for sorting. An online survey was created in which respondents could select which of a series of nominal categories 
best represented each item. These categories corresponded to the subfacet names that were proposed a priori (organizational policies and incentives for healthy weight, weight-related information and programs, leadership support for healthy weight, coworker support for healthy weight, healthy diet norms, exercise norms), along with an extra category entitled "Other." Participants were told that some items would be positively related to the category, whereas others would be negatively related (the reverse-coded items).

The participants in the holdout sample received an email containing a description of the purpose of the study, an offer of the same incentive used in the first part of the item generation portion, and a link to the survey. As before, participants were first shown an electronic consent form and asked to provide their consent electronically. After this, participants completed the sorting task and entered their information only if they desired to receive the incentive.

Responses were coded with the numbers 1 through 7 to identify the category into which each respondent sorted each item. Fleiss' kappa (Fleiss, 1981) was then used to assess inter-rater agreement on each item. The Fleiss statistic was deemed appropriate in this instance as both the number of raters and the number of nominal response categories was greater than two. Using the rule of thumb proposed by Landis and Koch (1977), indicators with substantial agreement, $x=0.61$ or higher, were initially retained for pilot testing. This resulted in a total of 39 items being retained.

\section{Stage 1 Discussion}

In this first stage of the study, a large pool of possible items was obtained from a survey containing questions about respondents' weight-related experiences and perceptions in the workplace. The questions were designed to gather information relating to six specific factors that were hypothesized a priori, based on previous research relating to health and climate: organizational policies and incentives, weight-related information and programs, leadership support for healthy weight, coworker support for healthy weight, healthy diet norms, and exercise norms. Respondents 
provided a total of 316 preliminary items as a result of this survey, and these items covered a broad range of topics. Even after these items were initially reduced through elimination of redundant or unusable items, a total of 77 items remained and at face value, it appeared that they broadly covered all of the originally hypothesized factors.

This set of items was next sent to a set of full-time employees who were asked to sort the items based on the factor structure that was proposed a priori. Participants were asked to look at each item individually and to decide into which factor it would best fit. Agreement was then computed, and the 39 items that had the strongest sorting agreement were retained. One thing that was apparent after this process was completed was that some of the factors seemed to be more wellsupported than others. As an example, several items were sorted into the healthy diet norms factor with near perfect, or perfect, agreement, while a large portion of items that were sorted into the weight-related information and programs factor and the organizational policies and incentives factor were often interchanged by participants. That is, while a majority placed them into one category, a sizeable portion of individuals also placed them into the other category. Even with the items retained from these factors based on sufficient interrater agreement, this pattern could be seen. This provided an early indication that perhaps the originally proposed factor structure was not going to be replicated exactly as envisioned once responses to the items were gathered.

With a preliminary set of items created, it was necessary to assess how these items actually functioned in relation to one another. To this end, the second stage of the present study involved pilot testing the new set of items on a sample of full-time employees. The goals of this stage of the study were to identify the factor structure that best fit the responses to the items and to reduce the number of items so that only the most reliable and informative items were retained. 


\section{CHAPTER 3: STAGE 2 - PILOT TESTING}

\section{Participants}

Participants for the pilot testing study were alumni of a mid-size Southern university who were employed full-time outside of their homes. Participants were recruited via email. A total of 379 completed surveys were received in response to 947 emails, a response rate of $39.92 \%$. Of these surveys, 41 were discarded for insufficient data or obvious mindless responding (e.g., providing the same response for every item in a category, even when some items were negatively worded), yielding a final sample size of 338 individuals.

\section{Procedure}

Participants were recruited through emails sent by the researcher to active members of the university's alumni association. The list of alumni names and information was obtained, and a random sample of 1,000 individuals was chosen from the list. The only criteria for inclusion in the list was that the individuals must have reported being employed at the time of the last biennial survey. Emails were then sent to each of these individuals, requesting participation in the study. The emails contained a brief description of the purpose of the study, an offer of a $\$ 10$ electronic giftcard to a major online retailer in return for completion of the survey, and a link to the survey items. Fiftythree of these emails were found to be invalid or the mailboxes were indicated as being full, putting the final number of initial contacts at 947.

Participants who clicked on the survey link were first asked to read an informed consent document and to determine whether they wish to proceed. Those who indicated consent through electronic signature were then forwarded to a set of screening items. These screening items asked if the individual was currently employed full-time, and whether the individual had been employed in the present organization for at least 6 months. Any participant who provided an answer of "No" to either of these questions was automatically redirected to a disqualification page. The latter 
requirement for length of employment was used in an effort to ensure that respondents could be reasonably expected to be familiar with the climates in their respective organizations.

Participants who passed the screening questions viewed the 39 pilot items in sets of ten items per page. The order of these items was fully randomized, so that no two individuals received the items in the same sets, or in the same order within sets. The number of items on each page was limited to ten in an effort to reduce mindless responding due to the long length of the survey. Participants were asked to think about their own organizations, as well as the people with whom they worked, while answering the items. Following completion of the pilot items, participants were asked to complete a set of demographic items, and to provide their names and email addresses if they wished to receive the incentive. Those who wished to remain anonymous could opt not to provide this information, although this resulted in forfeiture of the incentive.

\section{Measures}

The items retained at the end of Stage 1 were included in the study. A five-point Likert-style response scale was used for these items, ranging from Strongly Disagree (1) to Strongly Agree (5).

The demographic items included in Stage 2 were identical to those used in Stage 1.

\section{Results}

To begin assessing the underlying latent factor structure of the scale, responses to the pilot items were analyzed using exploratory factor analyses (EFA). Specifically, principal axis factoring using Promax (oblique) rotation with Kaiser normalization was utilized. Although an orthogonal rotation often produces a rotated factor structure that is easier and cleaner to interpret, an oblique rotation was chosen primarily for the fact that as hypothesized facets of a higher-order construct, the subscales were expected to correlate with one another to at least a certain extent. Reise, Waller, and Comrey (2000) provided additional support for the use of oblique rotation in their work on 
factor analysis and scale revision, demonstrating a slight advantage in factor replicability and the inclusion of beneficial information about intercorrelations.

An initial EFA was conducted with the purpose of identifying the major factors and eliminating items that either did not load strongly on any factor, or exhibited significant crossloading on multiple factors. As there is no consistent agreement as to how best to determine the number of factors to retain, a variety of criteria were considered in making this judgment. Factors were considered for retention if they had an eigenvalue greater than 1 , were located on the scree plot prior to the point at which the slope leveled off, had at least three items with factor loadings of 0.30 or more (Cabrera-Nguyen, 2010; Reise, Waller, \& Comrey, 2000; Streiner, 1994). Using these criteria together, three factors were identified for which retention seemed clearly warranted, and a fourth factor was on the borderline. This fourth factor had an eigenvalue of .98, just below the cutoff of 1 , but it did have more than the minimum of three items, it accounted for an additional $4 \%$ of variance, and its items did not crossload significantly. Because some studies have demonstrated that overextraction is preferable to underextraction (Fava \& Velicer, 1992; Wood, Tataryn, \& Gorsuch, 1996), this fourth factor was retained for later analyses.

Next, items that did not cleanly load on one of these four factors were eliminated. Following the suggestion of Costello and Osborne (2005), items that showed loading values equal to, or greater than, 0.30 on two or more factors were eliminated. Items were deleted in descending order of strength of cross-loading with the EFA being re-run after each deletion. This iterative process resulted in a total of 24 of the 39 items being retained. When the items within the factors were examined, the four factors appeared to be as follows: general organizational support, with 8 items; healthy diet norms, with 6 items; social support for healthy weight, with 6 items; and belittling and distrusting behavior, with 4 items. These items and their respective factor loadings are shown in Table 1. 
In examining the items that were not retained as a result of the EFA, a few themes emerged. First, items that were originally sorted into social support for exercise tended to have high levels of crossloading with the retained factors of social support and general organizational support. These items mainly focused on exercising together, or encouraging fellow employees to exercise (e.g., "My coworkers often work out together"), and may have been picking up on social support that was the result of organizational policies or programs promoting exercise at work. There were also several items that loaded most heavily on a factor for which there were only one or two items. For instance, the item "I enjoy being active with my coworkers" loaded highly on its own factor, but crossloaded with the social support factor that was retained. Finally, the majority of the leadership items were eliminated due to heavy crossloading. Rather than forming their own factor, these items tended to load fairy strongly across all retained factors. Only a few leadership items were retained because of this.

Next, the internal consistency reliability of each facet was examined. Coefficient alpha (Cronbach, 1951) was computed for the items retained in each subscale, along with the alpha value if each item were deleted. Only one item, "Managers in my organization encourage participation in weight maintenance programs," which was part of the general organizational support scale, resulted in an increased alpha value if deleted, raising alpha by a value of .02. Because this facet of the scale already contained several more items than the other facets, the decision was made to remove it. With this item removed, the alpha values for the four facets were as follows: general organizational support, $\alpha=.90$; healthy diet norms, $\alpha=.88$; healthy diet norms, $\alpha=.87$; belittling and distrusting behavior, $\alpha=.79$.

Finally, item response theory (IRT) was used to further reduce and refine the scale. IRT is useful for scale reduction because IRT techniques allow for more accurate examination of the psychometric functioning of each item, as well as the scale as a whole. Broadly speaking, IRT allows 
for estimation of latent levels for a given trait based upon both the responses given by the respondents and the properties of the items themselves. Thus, unlike methods based on classical test theory, IRT analyses are not solely sample-dependent. Each item has a given set of characteristics that are invariant across the population. The results of IRT analyses allow for information to be gathered about the items in a test and their individual and interactive functioning while also understanding the response patterns of the test-takers (Embretson \& Reise, 2000).

The IRT outputs of primary interest in Stage 2 were the discrimination parameter, the person parameter, theta, and the point at which each item provides maximal information. Theta takes into account response patterns as well as the properties of the items themselves to estimate each individual's standing on the latent trait of interest. Theta is distributed standard, normal such that a score of $\square=0$ represents average standing on the trait and positive and negative values represent scores above and below the average, respectively. In a polytomous IRT model with ordered categories, the difficulty parameters $(b)$ indicate what level of theta is needed before an individual has a 50\% chance of endorsing the next response option. An item in a polytomous model will have a number of difficulty parameters that is one less than the total number of response options, such that $b_{1}$ indicates the level of theta necessary to have a $50 \%$ probability of moving from response 1 to response 2, and so forth. The discrimination parameter (a) determines the slope of the response function at these various points and indicates how accurately an item can differentiate between those at higher and lower levels of theta. Positive values indicate more discriminating items, making large discrimination parameters more desirable. Finally, the amount of information that an item provides across the continuum of theta can be graphed, making it possible to determine the value(s) of theta for which an item is maximally predictive. For more information on IRT, please see the works of Embretson and Reise (2000) or DeAyala (2009). 
The goal of the present study was to produce a relatively short measure that still maintained psychometric fidelity, and the item and person parameters discussed above were examined to obtain this goal. First, MULTILOG computer software (Thissen, 1986) was utilized to estimate item parameters using the graded response model (GRM). The GRM can be used in situations where polytomous item responses are assumed to represent ordered categories (Samejima, 1997), making it appropriate for use with the proposed scale. Each scale facet was examined separately, as this particular model is not suited for multidimensional scales. Within each facet, items were selected in or out of the scale depending upon their combination of discrimination and level of information. The ideal was to find a set of items, each with high discrimination values, that together, provided significant information across the range of theta. To that end, items were directly compared to one another and were eliminated if there were alternative items with superior combinations of these qualities (i.e., if two items showed equal information at a given level of theta but one was more discriminating, the less discriminating item was eliminated). As with the EFA, the IRT analyses were rerun after each item elimination occurred, as parameter estimates can shift when items are added or removed.

Table 2 displays the parameters for each item tested in this set of analyses. In this table, items that were retained for further use are indicated through highlighting, and the displayed parameters are those obtained in the final iteration for which each item was included. In total, 10 items were eliminated as a result of the IRT analyses: 3 items from the general organizational support subscale, 2 from healthy diet norms, 1 from social support for healthy weight maintenance, and all 4 from belittling and distrusting behavior. This resulted in 5 general organizational support items, 4 healthy diet norms items, and 5 social support for healthy weight maintenance items being retained, for a total of 14 items. Figures 1 through 4 show the test information for each facet of the scale. 
As a final step in the IRT analyses, model fit for each of the reduced subscales was assessed using MODFIT (Stark, 2001). The tests of the lower-order margins demonstrated acceptable model fit for each of the subscales. Specifically, the chi square/df values for each of the subscales were within acceptable levels (e.g., less than 3.0). For the general organizational support scale, all singlets had a $x^{2} / \mathrm{df}$ ratio of less than 1 , and the average value was .44. Model fit results were similar for the social support subscale, which has an average $x^{2} / \mathrm{df}$ ratio value of .51 , and for the diet norms scale, with an average $x^{2} / \mathrm{df}$ ratio value of .88 .

\section{Stage 2 Discussion}

In this portion of the study, the preliminary set of 39 items was reduced to fourteen through the use of exploratory factor analysis, analysis of scale reliability, and item response theory. An iterative process was used with all analyses, such that the analyses were re-run after removing the lowest performing item after each analysis. Poorly performing items were defined as those with excessive crossloading in the EFA (greater than .30 on two or more factors), those for which removal would result in increased subscale reliability, and those for which IRT analyses indicated that another item provided a better combination of information and discrimination at a particular level of theta. Four items were removed as a result of the EFA results, one was removed in order to increase the reliability of its subscale, and 10 were removed during the IRT phase, including all four items from one of the subscales.

Perhaps the biggest surprise from this stage of the study was that the results of the EFA were so dissimilar to the factor structure that was originally envisioned. Based on preliminary readings, as well as examination of other climate and health-related scales, a 6 -factor solution was expected. When the EFA was conducted, however, only four factors seemed prominent. Furthermore, one of these factors, which was labeled "belittling and distrusting behavior" was not originally proposed. Each of the items within this scale were originally sorted (in Stage 1) into the 
same factor as the social support items, indicating that most respondents likely envisioned them as representing the negative end of the social support spectrum. Three of the four items that loaded on to this factor did have low-level crossloading on the social support factor (values of .21 to .25), but this crossloading was not high enough to indicate that the items were actually tapping the social support construct. Based on the results of the EFA, it would seem that these items did represent a distinct, unexpected factor of negative interpersonal mistreatment relating to weight maintenance.

Although these items were certainly interesting, and seemed to represent a unique aspect of the proposed weight maintenance climate, the decision was made to eliminate this factor based on the IRT analyses. When the information plots for each item were examined, it was apparent that these items yielded extremely low information across the entire range of theta. Figure 5 displays the information plot for the item with the strongest factor loading, "If I participated in a company weight loss program, I'd be worried about being made fun of by the managers," and even this item had an almost null level of information. This plot is representative of the remaining three items from this factor, with the others having similar or even lower levels of information. Furthermore, Embretson and Reise (2000) suggest that a test have a cumulative information value of around 10, and the sum of the information values for these items fell well below that. A primary goal of this study was to produce a scale that was both brief and psychometrically sound, and the elimination of this subscale addressed both of these things by shortening the overall length and removing items with little psychometric value.

The remaining three factors that were identified and retained in this stage of the study did map on to factors that were originally hypothesized. The first of these factors, which formed the general organizational support subscale, includes items that address individuals' perceptions of how much their organizations support weight maintenance. This particular subscale not only had the strongest item factor loadings, but also had the highest reliability and provided the greatest level of 
overall information (see Figure 1 for the test information plot) out of the three retained factors. A possible explanation for these findings is that at least some of these items may have required less subjective judgment on the part of the respondents: if an organization has weight-related policies or practices, that is probably an obvious thing to most employees. The other two factors involved perceptions of social constructs (healthy diet norms and social support) which may have involved more ambiguity and left more room for subjectivity and inconsistencies in responding.

Another possible reason for this, and especially for the higher levels of information provided, is that the items from the general organizational support scale may have been more directly tapping the main construct of healthy weight climate. In examining the items, those from the general organizational support scale are fairly broad, representing general perceptions of the overall organization. For the other two subscales, the majority of the items are much more specific, focusing on discrete behaviors such as snacking, talking to others about weight maintenance, and bringing unhealthy foods into the workplace. Because of the specificity of these items, each individual item may not have provided as much information about the broader constructs that the subscales were designed to assess.

Although the general organizational support subscale was psychometrically strongest, the healthy diet norms and social support subscales also performed well in the analyses. Together, these two subscales accounted for an additional 29\% of the variance in the EFA analysis, and both subscales provided a good amount of information across a broad range of the underlying latent traits. The inclusion of these scales is also consistent with previous literature on climate, which indicates that climate includes shared perceptions of the informal, social aspects of an organization (Denison, 1996; Reichers \& Schneider, 1990).

Stage 2 of the present study resulted in the creation of what was hoped to be the final version of the climate for healthy weight maintenance scale. However two important aspects of this 
scale were yet untested: the scale's construct validity (that is, was it actually measuring climate in relation to maintenance of a healthy weight) and the appropriateness of aggregating scores to the group-level, as would be expected with a climate measure. In stage 3, both of these issues were addressed. The new composite and individual subscale responses were assessed in relation to multiple other constructs that could be expected to form a nomological network with the construct of climate for healthy weight maintenance, with hypothesized relationships shown in Table 4. Multilevel modeling was also utilized in an effort to demonstrate that the variance in responding could be more strongly attributed to group membership than individual-level factors. 


\section{CHAPTER 4: STAGE 3 - APPLIED TESTING AND CONSTRUCT VALIDATION}

\section{Participants}

Participants in the applied testing portion of the study were 360 full-time employees of various organizations across the United States. A total of 26 organizations were represented in the

present study, and the number of participants from each individual organization ranged from 9 to 19 $(M=13.80, s=3.31)$. The overall sample contained slightly more men $(n=199,55.26 \%)$ than women, and the majority of participants self-identified as being White/Caucasian $(n=240,66.67 \%)$. The remaining participants self-identified as Black/African American ( $n=58,16.11 \%)$, Asian/Pacific Islander $(n=22,6.11 \%)$, Hispanic/Latino $(n=17,4.72 \%)$, Middle Eastern $(n=15$, 4.17\%), Multiracial $(n=5,1.39 \%)$, and Native American/American Eskimo $(n=3,0.83 \%)$ Table 3 shows the breakdown of number of participants by organization, and the location of each organization, along with basic demographic information for each organization.

\section{Procedure}

Organizations were recruited in two different ways. Six organizations were local to the researcher and were recruited through one-on-one meetings between the researcher and a manager. Preliminary contact was made either via email or phone calls, followed up with the meeting to discuss study details. The remaining twenty organizations were recruited through a networking approach, sometimes colloquially referred to as a snowball technique (Salganik \& Heckathorn, 2004). The networking approach involved seeking referrals for possible participating organizations from colleagues, and then seeking referrals from those who chose to participate. A total of eleven individuals known to, but not related to, the researcher were contacted and asked to provide the contact information for organizations that might be open to having their members surveyed. These individuals were asked to refer organizations that were not their own. The organizations were then contacted, and the individuals who referred them were compensated with a $\$ 25$ giftcard to a major 
online retailer if at least one organization agreed to participate. When participants from these organizations were surveyed, they were also offered the opportunity to refer other organizations by directly emailing the researcher, with the same incentive offered as a sort of "finder's fee." This networking approach was used in an effort to reach a broad range of organizations from different locations and in the past, has been shown to be useful in this respect (e.g., Lewis \& Malecha, 2011; Yancey, Cochran, Corliss, \& Mays, 2003).

When a referral came in, the researcher contacted the organization via phone or email, depending upon the information available for that particular company. The purpose and details of the study were discussed with a manager, or team of managers, and permission to survey employees was sought. Because the surveys were electronic, and because anonymity was desired due to the sensitive nature of some of the questions, managers from participating organizations were sent an email that they were asked to forward to employees. This email contained a statement of the study's purpose, assurances of anonymity, an offer of a $\$ 10$ giftcard to a major online retailer in return for participation, and a link to the survey. Due to financial limitations, it was important that no more than 20 participants were drawn from each organization. Therefore, the emails also contained a statement that the survey was open on a first come, first served basis, with only the first 20 respondents from any given organization being allowed to complete the study. Organizations were identified using a code (first letter of organization name, followed by the organization's zip code), and the system software was checked regularly and set to reject respondents once the 20 participant mark was reached. No identifying information was gathered regarding organizations beyond the zip code.

Employees who chose to participate first viewed an informed consent document and if they indicated consent through an electronic signature, they were asked to complete the full survey. The survey consisted of the scale items retained from Stage 2 along with the convergent and discriminant 
validation scales and demographic items. Upon completion, each participant was offered the opportunity to enter an email address at which to receive the incentive. No names were collected, and the organizational code was the only identifying information. On this same page, a statement was provided that indicated that participants could directly email the researcher at a provided email address if they wished to provide referrals. This cycle was then repeated until a sufficient number of individuals and organizations had been reached and funding for incentives had been exhausted.

\section{Measures}

Diet Quality General quality of participants' diets was assessed using a custom twelve-item scale. Existing measures of diet health/quality (e.g., Haines, Siega-Riz, \& Popkin, 1999; Kennedy, Ohls, Carlson, \& Fleming, 1995) are impractical for use in the present study as they require respondents to record details of all snacks and meals for several days. The custom scale was created with the assistance of two registered dietitians and was designed assess relative frequency with which six "good" and six "bad" foods are consumed. Each of the twelve items in the scale represents a specific type of food, such as leafy green vegetables and lean protein on the "good" side, and salty/fried foods and full fat dairy on the "bad" side. Participants were asked to estimate the frequency with which they consumed each of the twelve food types and to indicate this frequency using a Likert scale. The eight-point scale range from never to five or more per day, and one of the eight options was an unscored response option which allowed participants to indicate which foods they could not eat due to dietary restriction (allergies, medical restrictions, etc.) or for religious/ethical reasons. Participants endorsing the unscored response option for any item were removed from analyses related to diet quality. Scoring involved reverse coding the "bad" food items, then creating a summed score across all items. Thus, a higher score was indicative of a better diet quality. 
Health Motivation Health motivation was measured using an eight-item scale developed by Moorman (1990). The items presented statements regarding motivation to develop and maintain healthy behaviors. An example item would be "I try to prevent health problems before I feel any symptoms". Respondents indicated the extent to which they agreed with each statement using a fivepoint Likert scale that ranged from Strongly disagree (1) to Strongly agree (5). Although the original measure used a seven-point Likert scale, the five-point scale was used for the sake of consistency across measures.

Health Knowledge Health knowledge was measured using a ten-item scale designed by Moorman (1990). In this scale, two lists of items were presented, one including ten nutrients and vitamins and one including ten health outcomes. Participants were asked to match each nutrient or vitamin with the health outcome with which it is primarily associated. An incorrect response for an item was coded as 0 , and a correct response coded as 1 , so that each participant's score was the number of correct matches which he or she was able to provide.

General Health General health was measured using the Physical Symptoms Inventory (Spector \& Jex, 1998). Each of the eighteen items presented a somatic symptom which an individual might experience. For each of the items, respondents were asked to think about their health over the past month and to indicate if they had not experienced the symptom (0), had experienced it but had not visited a doctor (1), or had experienced the symptom and had visited a doctor because of it (2). Higher scores on this measure are indicative of increased health problems, or lower general health.

Body Mass Index Respondents were asked to provide their height, in feet and inches, and weight, in pounds, when responding to the demographics section of the survey. Body mass index (BMI) was then calculated from this information using the standard formula (Garrow \& Webster, 1985): (weight in pounds x 703) / (height in inches, squared). For the purposes of interpretation, BMI scores can be used to classify individuals into specific weight categories using 
the World Health Organization's (www.who.int) guidelines for weight category: BMI <18.5underweight; 18.5 to 24.9- healthy weight; 25 to 29.9- overweight; BMI equal to or greater than 30obese.

Worksite Support for Health Worksite support for health-oriented behaviors was measured using a subscale of the Leading by Example Instrument (LBEI; Della, DeJoy, Goetzel, Ozminkowski, \& Wilson, 2008). The three-item Worksite Support for Health Promotion subscale of the LBEI assesses workplace incentives to adhere to healthy lifestyle practices. Each item presented a statement regarding health incentives and respondents indicated the extent to which they agreed or disagreed. Respondents used the same five-point Likert response scale utilized for the health motivation scale.

Leadership Support for Health Support provided by organizational leadership for general health promotion activities and behaviors was also measured using the LBEI (Della, DeJoy, Goetzel, Ozminkowski, \& Wilson, 2008). The three-item Leadership Support for Health Promotion subscale of the LBEI assesses leadership members' training about, and commitment to, promoting health among employees. Each item presented a statement regarding leadership support for health and respondents indicated the extent to which they agree with each statement using the same fivepoint Likert scale.

\section{Existing Measure of Health Climate One existing measure of health}

climate was used in the present study. This measure, the Worksite Health and Safety Climate measure (Basen-Engquist, Hudmon, Tripp, \& Chamberlain, 1998), contains 11 items, 6 categorized as assessing safety and 5 as assessing health. For the purposes of the present study, only the 5 healthrelated items were needed. Each item present a statement regarding health-related behaviors, policies, and norms within an organization and respondents indicated the extent to which they 
agreed or disagreed with each using the previously described five-point Likert scale ranging from 1 (Strongly Disagree) to 5 (Strongly Agree).

Although the author had originally proposed using the Workplace Health Climate Scales (Ribisl \& Reischl, 1993), this scale was not included due to the fact that the authors could not be reached to obtain the items and permission to use them.

Social Support for Exercise ‘Workplace social support for exercise behaviors was measured using a modified version of the scales developed by Sallis, Grossman, Pinski, Patterson, and Nader (1987). The original scales were designed to measure social support for exercise habits from two sources, friends and family. The items from the social support from friends scale were included in the present study, but the instructions were altered to reference "people with whom you work" rather than "your friends." The friends version of the scale was considered preferable to the family version because the latter contained additional items that were clearly only applicable to individuals sharing a domicile (e.g., "Took over chores so I had more time to exercise.")

The social support for exercise scale contained five items, each presenting an activity, behavior, or attitude that people at work could express to one another and which may support healthy exercise habits.. For each item, a stem was presented ("people with whom I work") and participants were asked to indicate the extent to which they agreed or disagreed with each of the statements using the same five-point Likert scale.

Physical Activity Physical activity was measured using a custom four-item scale created by the author. Each of the four items in the scale presented a form of physical activity, along with several examples of each, and respondents were asked to indicate how often they engaged in each of the forms of activity over the past month. Responses are provided using a six-point scale ranging from a frequency of none to six or more days per week. For the purposes of analyses, the lowest two frequency options (“Unable/not medically allowed to do this" and "Did not choose to do this") 
were both scored as 0 . This scale, tentatively named the General Physical Activity Scale, is in the process of being validated and preliminary data show that it is strongly predictive of physiological measures of physical fitness and has good convergent and discriminant validity.

Instructions, items, and response and scoring information for this, and all other customcreated measures for Stage 3, are presented in Appendix A.

\section{Results}

The data were first examined using a confirmatory factor analysis (CFA). The CFA was used to assess whether the factor structure identified in Stage 2 adequately described the data gathered in an applied setting. This is important to make sure that the final 3-dimensional structure identified in Stage 2 did not capitalize on chance by overfitting that particular data set. Additionally, a priori competing models were developed for testing in an effort to ensure that if the primary model showed inadequate fit, any further models tested would not merely be the result of guessing and checking (Jackson, Gillaspy, \& Purc-Stephenson, 2009). To this end, the originally hypothesized model was tested (three subscales tested as latent variables subsumed within an overall healthy weight climate latent variable) along with two alternatives. In the first alternative model, the latent variables of general organizational support, social support, and diet norms were allowed to covary, and no overall climate variable was included. In the second alternative model, the overall climate variable was included, but no subscale variables, so that all 14 items were directly linked to the single latent healthy weight climate variable. Prior to the CFA analyses, missing data were imputed through maximum likelihood imputation in PRELIS, and all variables were standardized to z-scores.

Model fit index values and degrees of freedom for all models, as well as an independence (entirely constrained) model, are shown in Table 5. Fit indices included in this table are chi square $\left(x^{2} ; 229.59\right)$, ratio of the chi square value to degrees of freedom $\left(x^{2} / d f ; 3.10\right)$, root mean square error of approximation (RMSEA;.08), normed fit index (NFI; .90), and comparative fit index (CFI; .87). 
A pictorial representation of the hypothesized model, with standardized coefficients, is provided in Figure 6. The hypothesized model showed the best fit of the four included in the analyses and in general, its fit was acceptable.

Prior to examining the construct validity hypotheses, multilevel modeling was used to determine whether sufficient variance in climate scale responses was explained by group membership to allow for aggregation to the group level. To this end, a null, or no predictor, model was analyzed in order to partition the variance in the four scales measures (overall scale and three subscales) between the individual level and the group level.

The results of this null model testing indicated that significant variance in the overall climate for healthy weight maintenance scale could be explained by group membership (Wald $\mathrm{Z}=12.21, p$ $<.001$, ICC $=.57)$. Similar results were found for all three subscales: general organizational support (Wald $\mathrm{Z}=12.85, p<.001, \mathrm{ICC}=.59$ ), healthy diet norms (Wald $\mathrm{Z}=12.92, p<.001, \mathrm{ICC}=.53$ ), and social support for healthy weight maintenance (Wald $\mathrm{Z}=12.86, p<.001$, ICC $=.60$ ). This provided support for hypothesis 1, which proposed that there would be sufficient within-group agreement, in comparison to the between-group variance, to justify aggregation to the group level.

Next, the convergent and discriminant validity of the composite climate scale was assessed by examining the simple correlations between the climate composite and subscales and the validity measures. The correlations among all demographic and validation variables, along with mean item responses and standard deviations, are shown in Table 6. Following the recommendations of Cohen (1992), correlation strength was quantified as follows (absolute values shown for the sake of clarity): None or very weak, lower than 0.10 ; weak, 0.10 to 0.30 ; moderate, 0.30 to 0.50 ; and strong, 0.50 to 1.00 .

Hypothesis 2 proposed a moderate positive correlation between climate for healthy weight and self-reported physical activity level. This hypothesis was supported for the composite scale $(r=$ $.39, p<.01)$ as well as the healthy diet norms subscale $(r=.36, p<.01)$ and was borderline 
supported for both the general organizational support and social support subscales $(r=.29, p<.01)$. Hypothesis 3 proposed a moderate positive correlation between climate for healthy weight and selfreported diet quality. This hypothesis was supported for the composite scale $(r=.39, p<.01)$, the general organizational support subscale $(r=.39, p<.01)$, and the healthy diet norms subscale $(r=$ $.45, p<.01)$. The correlation between diet quality and the social support subscale was on the upper end of weak $(r=.24, p<.01)$, but was not quite strong enough for hypothesis 2 to be fully supported for this subscale.

Hypothesis 4 proposed a moderate positive correlation between climate for healthy weight and health motivation. This hypothesis was supported for the composite scale $(r=.34, p<.01)$, the general organizational support subscale $(r=.33, p<.01)$, and the social support subscale $(r=.31, p$ $<.01)$, but was not supported for the diet norms subscale $(r=.18, p<.01)$.

Hypothesis 5 proposed a weak positive correlation between climate for healthy weight and diet-related health knowledge. This hypothesis was supported for the composite scale $(r=.13, p<$ $.05)$, and the social support subscale $(r=.25, p<.01)$, but was not supported for either the diet norms subscale $(r=.03, p>.05)$ or the organizational support subscale $(r=.06, p>.05)$.

Hypothesis 6 proposed a weak negative correlation between climate for healthy weight and physical health problems. This hypothesis was supported for the composite scale $(r=-.26, p<.01)$ and all of the subscales: general organizational support $(r=.-.22, p<.01)$, diet norms $(r=-.26, p<$ $.01)$, and social support $(r=-.13, p<.05)$.

Hypothesis 7 proposed a moderate negative correlation between climate for healthy weight and body mass index (BMI). This hypothesis was not supported for either the composite scale $(r=$ $.18 p<.01)$ or the subscales: general organizational support $(r=.-.16, p<.05)$, diet norms $(r=-.21$, $p<.01)$, and social support $(r=-.13, p<.05)$. Although all correlations were significant and in the hypothesized direction, they did not meet the criteria for being considered moderate in strength. 
Hypotheses 8 through 11 involved assessing correlations between the climate scale and validation measures at both the individual and group levels. For group-level correlations, both the predictor and the criterion measures were grand-mean centered and then aggregated to the group level, so that each individual within an organization had the same values.

Hypothesis 8 proposed a moderate positive correlation between climate for healthy weight and an existing scale assessing organizational support for general health (not weight-specific) at both the individual and organizational level. At the individual level, the correlation $(r=.54, p<.01)$ was slightly higher than is considered moderate (.50), and the difference was even stronger at the group level $(r=.63, p<.01)$. The hypothesis could not be supported as written, because both of these correlations qualify as strong rather than moderate.

Hypothesis 9 proposed a moderate positive correlation between climate for healthy weight and an existing scale measuring leadership support for general health (not weight-specific) at both the individual and organizational level. Similar to the above hypothesis, the correlations were stronger than predicted at both the individual $(r=.59, p<.01)$ and organizational level $(r=.61, p<$ .01). Again, the correlations qualified as strong rather than moderate, meaning that hypothesis 8 was not supported as written.

Hypothesis 10 proposed a strong positive correlation between climate for healthy weight and an existing scale measuring general health climate (not weight-specific) at both the individual and organizational level. This hypothesis was supported at the individual level $(r=.62, p<.01)$ and the organizational level $(r=.64, p<.01)$.

Hypothesis 11 proposed a moderate positive correlation between climate for healthy weight and an existing scale measuring social support exercise at both the individual and organizational level. The correlations at both the individual $(r=.51, p<.01)$ and the organizational level $(r=.55, p$ 
$<.01)$ were both slightly higher than is considered moderate, meaning that the hypothesis was not supported as written.

\section{Stage 3 Discussion}

In the final stage of the present study, a sample of full-time employees from several states completed the newly created climate scale, as well as measures of several constructs intended to test the scale's convergent and discriminant validity. In addition to these validation analyses, the scale was also assessed using confirmatory factor analysis and multilevel modeling analysis. The goal of the former was to determine whether the factor structure hypothesized as a result of the Stage 2 exploratory factor analysis was replicated. The multilevel analysis was used because climate is a group-level variable, and sufficient within-group agreement in responses must be demonstrated before aggregation of data to that higher level can be justified.

The results of the CFA provided evidence that the proposed factor structure for the climate for health weight scale was supported. Although the model fit was not perfect, the majority of the fit indices were within, or very close to, the desirable ranges, and the fit for the main model was clearly superior to the fit of any of the alternate models that were tested. For the main model, the $x^{2} / d f$ value of 3.10 may be considered slightly high by some researchers (Byrne, 1989), but would be considered well within the acceptable range by others (Marsh \& Hocevar, 1985) who have suggested that values as high as 5.00 can indicate a satisfactory level of model fit. The NFI value of .90 is right at the suggested lower limit of .90 (Bentler \& Bonett, 1980), but the RMSEA value of .08 is clearly below the suggested upper limit of .10 (Browne \& Cudeck, 1993) and the CFI value of .87 is much closer to the ideal value of 1.00 than any of the other models.

Examination of the modification indices revealed that the fit of the main model could be improved slightly be allowing certain items to correlate with one another. When the item "My organization actively promotes maintenance of a healthy weight" was allowed to correlate with the 
items "My organization does more to promote healthy weight than other organizations I know" and "My organization truly cares about helping individuals stay fit and healthy," and the item "My coworkers recognize one another for reaching and maintaining weight goals" was allowed to correlate with the item "If I started a new weight loss program, I know I could count on my coworkers for support", the fit indices were as follows: $x^{2} / d f=2.55, \mathrm{NFI}=.85$, RMSEA $=.07$, CFI $=.88$. Although these changes did improve the fit of the model, there are reasons to maintain the model as originally proposed, without the intercorrelations among indicators. At a conceptual level, changing a model as a result of statistical tests, rather than due to sound theoretical reasons, could be considered antithetical to the purpose of CFA. Not only is it theoretically unsound, but it could certainly result in overfitting the model to the data. Unless these few intercorrelations are tested and replicated in future research, it seems preferable to maintain the more parsimonious version of the main model.

This main model, shown in Figure 6, included four latent variables: the three subscale variables of general organizational support, health diet norms, and social support for healthy weight maintenance, as well as an overall climate for healthy weight maintenance variable. It was compared to two competing models, one which did not include the overall climate variable, and one which included only the single overall climate variable (no latent variables corresponding to the subscales). Neither of these competing models performed particularly well, indicating two things. First, this indicated that the three sets of subscale items are measuring unique aspects of the climate for health weight maintenance, each of which is distinct from the other. Second, this indicated that when these separate scales are taken together, they provide a combined estimate of a larger climate construct. This means that researchers and practitioners may be able to benefit from using both the subscale scores and the composite score when trying to understand weight-related behavior and experiences in the workplace. 
The preliminary hypotheses regarding validation measures were framed only in terms of the composite climate variable, but for the sake of better understanding the scale and its various facets, the validation analyses were conducted at both the composite and subscale levels. One thing that is clear from looking at the individual-level validation results is that all but one of the hypotheses were supported at the individual level. As expected, the composite climate measure correlated positively with physical activity, diet quality, health motivation, and health knowledge, and negatively with physical symptoms. This provided strong evidence of construct validity, by demonstrating that the new overall climate measure is relating to other measures in its nomological network in a manner that would be expected based on previous research.

The one variable with which the climate measure did not show the expected relationship at the individual level was with body mass index. It was originally hypothesized that climate for healthy weight maintenance would have a moderate negative correlation with BMI, and although the overall climate measure and its subscales did correlate significantly and negatively with BMI, the strength of these correlations was not high enough to be considered moderate. In retrospect, this finding is probably much more realistic than a moderate relationship. The main justification for the prediction of moderate strength was that as the physical manifestation of the climate for health weight maintenance, BMI should have a stronger relationship to the measure. However, this was probably an overly ambitious expectation for a few reasons. First, there are a vast number of factors that affect an individual's BMI, or level of body fat, other than a climate in his or her organization. These factors include genetics, socioeconomic status (Ball \& Crawford, 2005), the availability of healthy foods and areas for exercise where one lives (Boehmer, Hoehner, Deshpande, Brennan-Ramirez, \& Brownson, 2007), level of obesity during childhood (Laitinen, Power, \& Järvelin, 2001) and many others. Given the array of competing influences on this physiological measure, the strength of the correlations in the present study is likely quite impressive. 
Another possible explanation is that for some of the organizations in this study, the relationship may have been weakened as a result of recently increased weight maintenance efforts. That is, the climate for weight maintenance may have been stronger because individuals in those organizations were more adipose, and were therefore in more need of weight maintenance. For instance, it is feasible that some of the organizations in the study may have stepped up their weight maintenance efforts in an effort to combat obesity levels among employees. Weight loss, especially significant levels of weight loss, takes time, meaning that some of the organizations' weight maintenance climates may have been increased through organizational policies, social efforts among employees, and so forth, without significant BMI decreases manifesting at the time of the survey. This would have resulted in weakened correlations for individuals from these organizations, as climate levels would have been higher without significant decreases in BMI. If even a few of the organizations experienced such a phenomenon, it could mean that the correlation between climate and BMI would be closer to moderate in an established climate, but was weakened as a result of recently changed climates. Given that at least a portion of this data was collected in the early months of the year, and that the new year is a popular time for focusing on weight loss, this is not an implausible scenario.

For three of the four hypotheses about relationships at the organizational level, the opposite effect was found, with the relationships actually being stronger than expected. It was originally hypothesized that the existing general (not weight-specific) health-related scales of organizational support, leadership support, and social support for exercise would have moderate positive correlations with the newly developed scale. The rationale behind proposing a moderate correlation, as opposed to a strong correlation, was that each of these three scales was expected to relate primarily to only one aspect of the new scale. For instance, the organizational support for general health scale was hypothesized to correlate primarily with the organizational aspect expected to 
emerge in the new scale, and to correlate at a lower level with the other aspects of the scale. If this were the case, then the correlation with the overall composite scale would fall in between the single high correlation and the lower correlations with the other aspects of the scale.

However, as with the BMI-related hypothesis, the findings found for these scales seem to make more sense, when assessed post hoc, than the original hypotheses. It does seem likely that each of these validation scales would correlate more strongly with an individual subscale from the new scale, but it also seems likely that these scales would still correlate to at least a moderate level with all of the subscales. As different aspects of an overall climate, the subscales should intercorrelate with one another, so that an organization with a strong overall climate will have higher levels of all aspects of the scale than one with a weaker overall climate. There may be a few organizations in which the subscale measures differ significantly, but it would seem likely that this would not be the average experience. The correlations observed among the various subscales and the overall scale seem to back up this assertion. Because of this expected intercorrelation among the scales, any validation variable that correlates strongly with one aspect of the scale will likely have a relatively strong correlation with the other aspects of the scale. Thus, the originally proposed phenomenon of the validation correlations being pulled down to a lower average probably is not very realistic.

However, this only explains why the correlation with the overall scale might not be reduced moderate, and does not offer any explanation as to why the correlations of the older measures with the new weight-specific measure should be strong to begin with. One very plausible explanation as to why a strong positive correlation among the variables makes sense is that an organization which values health in general should show a definite valuing of a specific aspect of health such as weight maintenance, and vice versa. Perceptions, as the driving force behind a climate, could also play a role in this: if individuals within an organization have perceived that health, in general, is valued by the 
organization and its members, then they may be more apt to perceive that weight maintenance is valued, even if this has not been explicitly addressed. The alternate may also be true, with perceptions regarding weight maintenance climate influencing perceptions of general health climate. Because these two climates were so closely related at a conceptual level, it is not surprising that the correlations were found to be stronger than expected.

There are a few things worth noting with regards to these correlation interpretations. First, none of the correlations were so high as to indicate redundancy. The correlations are all on the lower end of strong, varying between a value of .54 and .64 , which indicates that the new climate measure and the existing general health climate-related measures are clearly measuring related constructs, as would be expected. At the same time, these correlations are far enough from perfect that it is apparent that the underlying constructs are distinct and do not overlap extensively. This means that researchers and practitioners can gather useful and distinct information from both the new and the older measures, and that the newly created measure is not simply a variation of existing health-related climate measures.

Additionally, the judgments of the strengths of these correlations were made using a very strict interpretation of Cohen's (1992) guidelines, and this may be impractical. One reason why this may be impractical is that the correlations provided were simple correlations with no corrections or controls. If the effects of extraneous variables were removed, the correlations might fall within the accepted range, and might actually provide a more accurate view of the relationships of interest. Even looking just at the raw correlations as they are, the interpretations made might be too strict. After examining the confidence intervals for the correlations that were deemed too high, all of the confidence intervals included values within the acceptable range. For instance, at the individual level, the correlation $(r=.54)$ between climate and organizational support for general health would be considered higher than the upper bound of moderate $(r=.50)$, but the confidence interval of .36 to 
.59 indicates that the true correlation may well lie within the moderate range. It is important that the generally minor differences between the original hypotheses and Cohen's boundaries not overshadow the real goal of construct validation, which is to show that the scale appropriately correlates with other related constructs. 


\section{CHAPTER 5: GENERAL DISCUSSION}

This study included three distinct stages of data collection and analysis, all with the purpose of creating a set of items to assess a newly proposed climate for health weight maintenance. Researchers and practitioners who are interested in understanding organizational and individual-level occupational health phenomena in the workplace often utilize measures of various climates to understand the antecedents and consequences of these phenomena. Measures of climate are especially useful when planning and executing interventions (Crump, Earp, Kozma, \& HerzPicciotto, 1996; Sorensen, Linnan, \& Hunt, 2004), and can serve as measures of the effectiveness of these interventions. Because the obesity epidemic has significant negative impacts on organizations (e.g., Finkelstein, Fiebelkorn, \& Wang, 2003; Neovius, Johansson, Kark, \& Neovius, 2008; Ricci \& Chee, 2005), interventions relating to maintenance of a healthy weight by employees could be very desirable for organizations. As the only measure of climate relating to healthy weight maintenance, it is clear that the scale created in the present study could prove useful to both researchers and practitioners.

Several analytical techniques were used to help ensure that the scale which was created was as psychometrically and theoretically valid as possible, which still remaining relatively brief in length. The latter constraint was added in an effort to create a scale that could be included in a battery of other measures without adding too much length. After a preliminary set of items was created, items were eliminated based on their information and discrimination parameters identified through item response theory, as well as through analysis of scale reliability and crossloading in an exploratory factor analysis. The final set of fourteen items were then completed by members of various organizations from across the United States, and multilevel analysis was used to determine whether aggregation to the group level was actually justified (a necessary characteristic of a climate, as it is assumed to be a group-level variable). Finally, the factor structure was confirmed using CFA in a 
new sample, and construct validity was established by demonstrating that the climate measure correlated with various other constructs that could be theoretically assumed to fall within its nomological network.

When taken together, the results of these analyses indicate several things about this newly developed scale. First, although the three-factor structure is quite different from that which was originally proposed, it does seem to be a model that functions well. When a CFA was conducted, the model fit was satisfactory for the hypothesized model that included the three subscales and an overall climate factor, and this model clearly outperformed two competing models which were also tested. Second, with a few exceptions, the validation hypotheses were supported at the composite level, and those that were not supported as written made intuitive sense when interpreted post hoc. This provided evidence that the scale is construct valid, or is actually measuring the psychological construct which it was designed to assess. That is to say, the newly created scale appears to be measuring factors in an organization that are related to maintenance of a healthy weight among employees, and that it is measuring something which is distinct from existing health-related climate scales. Lastly, the multilevel analysis indicated that more than $50 \%$ of the variance in responses for each subscale and the overall scale could be accounted for by group membership, but far less variance was accounted for at the individual level: overall climate scale: $12 \%$; general organizational support: $9.5 \%$; healthy diet norms: $16 \%$; social support: $13 \%$. Thus, it can be acknowledged with a fair amount of confidence that the new scale is assessing a climate, or a group-level construct comprised of shared perceptions, that are specifically related to maintenance of a healthy weight.

Although it was not of primary interest in this study, an interesting finding is that the various subscales do appear to have some variation in their relationships with the validation variables and demographic variables that were included in the study. This is a desirable thing, as each of the subscales is intended to contribute to the assessment of the overall climate, but to measure distinct 
components of this climate. These findings could prove useful to researchers or practitioners who are interested in understanding and influencing weight-related behaviors and outcomes in organizations. For instance, as can be seen in Table 4, the healthy diet norms subscale of the climate measure has a stronger correlation $(r=.45)$ with the specific health-related variable of diet quality than does the composite measure $(r=.39)$. A researcher who is primarily interested in organizational climate's relationship with variables relating to diet, then, would have the option of utilizing either the composite measure or just the subscale in his or her research. The latter may be a more desirable option if limiting the number of items is a concern.

\section{Limitations}

Although it does appear that this study resulted in the creation of a scale which was construct valid, showed stable factor structure, and provided significant information across a broad range of the construct being assessed, the current study is not without limitations. One limitation is that this study shared some of the challenges inherent to all literature on climates, simply due to the many requisite assumptions of climate measurement. That is, climate research typically measures the variable of interest at the individual level, then some process of aggregation is used as an indicator of climate at the group level. There are three major assumptions of this approach: 1) the climate-scale items describe objective situations rather than perceptions, 2) the employees within each group are exposed to the same situations, and will therefore describe them in the same manner, and 3) aggregating the individual responses will maximize similarities, and minimize the effects of individual differences (Jones \& James, 1979).

It is worth noting that at least two of these assumptions did appear to be justified in the current study. First, many of the items in the scale are descriptive rather than evaluative. For example, though there may be slight differences in responses to an item like "My organization provides information about how maintenance of a healthy weight is beneficial," on the whole, this 
item is more descriptive in nature. As such, affective reactions and perceptions should not play as large a role in responses to these items. Some of the other items (e.g., "My coworkers are more committed to maintaining a healthy weight than people I know in other organizations") may not satisfy this assumption, as there could clearly be differences in the way that individuals interpret and respond to this item. Second, to make sure that employees were exposed to the same situations, only employees who worked directly with each other, in the same workgroup, were included in the current study. Finally, aggregation appeared to maximize similarities, as the results generally showed high levels of within-group agreement on the climate for healthy weight maintenance. Thus, efforts were made to avoid common pitfalls of climate research, which can bolster confidence that the measure is truly assessing climate.

Another limitation of the current study is that the climate for health weight maintenance, as well as validation constructs, was assessed using only self-report measures. Often, researchers argue that self-report measures can be influenced by a variety of biases, and can largely be the result of perception (Podsakoff, MacKenzie, Lee, \& Podsakoff, 2003). As noted above, however, there was high within group agreement on the scale, indicating that individuals were likely measuring the same construct. It may have been possible to examine organizational written policies that involve employee health, in order to better objectively understand this climate, but these measures may also be flawed, given that organizations may have policies in place that are only loosely enforced or go unutilized. Additionally, as the current measure was created to measure climate, self-report may have been the best way to assess this. Climate, by definition, assesses the shared perceptions among individuals regarding a certain construct, and asking individuals to report their perceptions is probably the best way to understand a climate for healthy weight maintenance, or any climate.

Another limitation of the current study is that little is known about the organizations and workgroups from study 3 . That is, these organizations could have represented anything from fast 
food restaurants and grocery stores to law firms and doctor offices. Although the decision to keep the participants and organizations anonymous, with the exception of asking for location information, was made intentionally, this could be considered problematic in some ways. Because of this anonymity of the organizations, there was no way to examine characteristics of the organizations (e.g., size, industry type, hierarchical/managerial design) to see if, and how, these affected components of the scale. It is possible that the types of organizations, as determined by industry, size, and the like, might have an effect on the climate measure, as some types of organizations are quite different than others. It would have been interesting to see if organization type might actually predict facets of the climate, something that will be further addressed in the discussion of directions of future research.

Another limitation of this study was that the sample size could be considered low for some of the analyses. In Stage 2, the sample size of 338 participants is within the range found acceptable by Reise and Yu (1990), who used a Monte Carlo simulation to assess how many participants were needed to confidently estimate parameters using the graded response model utilized in the present study. The authors found that this model could be estimated with as few as 250 individuals, a value which is well exceeded in the present study, but that the best results were found with 350 individuals or more. Although not reported in the manuscript, the IRT analyses from Stage 2 were repeated using the Stage 3 sample of 360 individuals, and similar results were found. However, this is also a sample size that is close to 350 , meaning that sample size may still be a limitation for this analysis. That the results were similar across samples, however, provides additional levels of confidence.

Sample size could also be a concern in the CFA analysis. With 360 individuals representing 26 organizations, that yields an average of just under 14 individuals per organization. In their article on statistical power for multi-organization research, Raudenbush and Liu (2000) suggest that the optimal number of individuals from each organization is at least 14, meaning that the sample size in 
the present study fell somewhat short. Even with an average sample size close to that which is suggested, fully half of the organizations sampled had fewer than 14 respondents, with some organizations having as few as 9 individuals representing them. This could be cause for concern when interpreting the results of the CFA. At the same time, though, this could actually provide some indication as to why some of the fit indices were on the borderline. It is possible that the model would have had worse fit if tested on a larger sample, but it seems equally probable that the fit could actually have been improved, yielding even better fit index results.

A final limitation of the current study was the method used for recruiting participants. A networking approach was utilized to obtain respondents for the Stage 3 results, through which individuals known by the author were recruited, and those individuals could then recruit more people. This approach has been used with success in other studies (e.g., Lewis \& Malecha, 2011; Yancey, Cochran, Corliss, \& Mays, 2003), and is especially useful when researching sensitive or private issues, such as weight or weight-related constructs (Biernacki \& Waldorf, 1981). However, there are inherent issues when using this approach. First, this certainly yields a nonrandom sample, which may result in a sample which is biased toward certain personal characteristics. For instance, people who participate in an online snowball survey such as this likely have many social contacts, and have access to the internet. Faugier and Sargeant (1997) outline some other potential biases that could arise from the use of a snowball sampling method, such as social distance, overlapping acquaintance circles, and reflexive biases. Finally, because the sample is nonrandom, the results may be less generalizable to the population. It is difficult to tell, even if the sample does include individuals from different geographic locations, and of different demographic characteristics, whether these findings would hold up in other situations.

\section{Directions for Future Research}


There are several areas that should be considered for future research. First, the primary goal of the current study was to develop and validate a scale for measuring a climate for healthy weight maintenance. This scale appeared to function well in the current study, but it is always important to replicate factor structures and nomological networks when working with new scales (DeVellis, 2011). It would be important to continue to extend the nomological network of the scale, as well. One such option would be to examine whether there are any basic outcomes or consequences that can be related to a climate for health weight maintenance. Examples could include psychological outcomes within employees, such as burnout and engagement, or organizational outcomes, such as performance and healthcare costs.

Additionally, it would be interesting to see if the scale would function in the same way across different types of occupations. Some occupations might have characteristics in which a healthy climate is either easier or more difficult to maintain. For instance, in jobs that involve a lot of physical activity, such as laborers or line workers, employees already get quite a bit of exercise, even if it is not explicitly supported by management. As such, maintaining the social support portion of the climate may be easier or conversely, may not seem to matter as it may not be perceived as being needed. However, in these jobs, it may be more common for employees to eat junk food for lunch, making the diet portion of a healthy climate more difficult to maintain. Other types of occupations, such as office occupations, may be more sedentary, and employees may get almost no exercise as part of a job. As such, management may feel that they need to take more steps to encourage exercise. Occupation type, then, might be an important predictor of a climate for healthy weight, where simply working at a specific type of job might affect some of the facets of this climate. These speculative hypotheses could serve as a jumping off point for future research.

Another interesting area to investigate in relation to a climate for healthy weight maintenance would be to better understand how people's experiences may differ if their personal 
health values align with, or stand in contrast to, the health climate at work. Would employees be less engaged or satisfied if they have healthy personal values while working in a climate that was relatively unhealthy or conversely, might people who do not value a healthy lifestyle feel dissatisfied if the workplace is healthy? Understanding how a healthy climate could impact employees based on their own values could serve as a valuable tool for understanding important factors such as employee satisfaction and commitment, and employee retention.

A final area that could be investigated would be interventions for a healthy workplace environment, specifically with regards to healthy weight maintenance. As outlined in the preface to the current study, a workplace climate may have many beneficial effects on employees' behaviors. As such, it is worth investigating what organizations can do to encourage a healthy weight-related climate at work and how this could influence employees' weight-related behaviors. Workplaces could take small steps to encourage knowledge of healthy behaviors and assess if, and how, these affect perceptions (climate) at the group level and behaviors at the individual level.

The National Institute for Health and Clinical Excellence (NICE, 2008; United Kingdom) provides some recommendations for encouraging employees to be physically active, and some of these recommendations may be useful in cultivating a healthy workplace climate. One recommendation is that organizations should actively encourage movement in the workplace, such as by putting up signs at strategic points in the workplace and releasing notices that encourage employees to use the stairs and park further from the building. Another option is for organizations to utilize employee fitness competitions, such as competitions that track physical activity, or "Biggest Loser" competitions. One study by Brownell, Cohen, Stunkard, Felix, \& Cooley (1984) investigated a weight loss competition in which employees paid $\$ 5$ in to a pool, and the money was distributed to a winning team of employees. The results indicated that most employees lost weight, and that employee morale increased as a result. Though it was not investigated explicitly, competitions such 
as this might act to establish or reinfoece a climate for healthy weight maintenance. As such, organizations could potentially utilize weight loss competitions as a method for increasing the climate of health at work. 


\section{REFERENCES}

Aarons, G.A., \& Sawitzky, A.C. (2006). Organizational climate partially mediates the effect of culture on work attitudes and staff turnover in mental health services. Administration and Policy in Mental Health and Mental Health Services Research, 33(3), 289-301.

Avis, N.E., McKinlay, J.B., \& Smith, K.W. (1990). Is cardiovascular risk factor knowledge sufficient to influence behavior? American Journal of Preventive Medicine, 6, 137-144.

Ball, K., \& Crawford, D. (2005). Socioeconomic status and weight change in adults: A review. Public Health and Health Services, 60, 1987-2010.

Basen-Engquist, K., Hudmon, K.S., Tripp, M., \& Chamberlain, R. (1998). Worksite health and safety climate: Scale development and effects of a health promotion intervention. Preventive Medicine, 27, 111-119.

Bentler, P. M., \& Bonett, D. G. (1980). Significance tests and goodness of fit in the analysis of covariance structures. Psychological Bulletin, 88, 588-606.

Beus, J.M., Payne, S.C., Bergman, M.E., \& Arthur, Jr., W. (2010). Safety climate and injuries: An examination of theoretical and empirical relationships. Journal of Applied Psychology, 95(4), 713727.

Biernacki, P., \& Waldorf, D. (1981). Snowball sampling. Sociological Methods \& Research, 10, 141-163.

Boechner, L. S., Kohn, H., \& Rockwell, S. K. (1990). A risk-reduction nutrition course for adults. Journal of the American Dietetic Association, 90, 260-263.

Boehmer, T. K., Hoehner, C. M., Deshpande, A. D., Brennan-Remirez, L. K., \& Brownson, R. C. (2007). Perceived and observed neighborhood indicators of obesity among urban adults. International Journal of Obesity, 31, 968-977.

Browne, M. W., \& Cudeck, R. Single sample cross-validation indices for covariance structures. Multivariate Behavioral Research, 24, 445-455.3 
Brownell, K. D., Cohen, R. Y., Stunkard, A. J., Felix, M. R. J., \& Cooley, N. B. (1984). Weight loss competitions at the work site: Impact on weight, morale, and cost-effectiveness. American Journal of Public Health, 74, 1283-1285.

Byrne, B. M. (1989). A primer of LISREL: Basic applications and programming for confirmatory factory analytic models. New York, NY: Springer-Verlag.

Cabrera-Nguyen, P. (2010). Author guidelines for reporting scale development and validation results in the Journal of the Society for Social Work and Research. Journal of the Society for Social Work and Research, 1(2), 99-103.

Carmines, E.G., \& Zeller, R.A. (1979). Reliability and validity assessment: Quantitative applications in social science. Beverly Hills, CA: Sage Publications.

Centers for Disease Control and Prevention (n.d.) http://www.cdc.gov

Champion, V.L. (1988). Attitudinal variables related to intention, frequency, and proficiency of breast self-examination in women 35 and over. Research in Nursing and Health, 11, 283-291.

Claessens, M., van Baak, M.A., Monsheimer, S., \& Saris, W.H.M. (2009). The effect of a low-fat, high-protein, or high-carbohydrate ad libitum diet on weight loss maintenance and metabolic risk factors. International Journal of Obesity, 33, 296-304.

Cobb, L., Stone, W., Anonsen, L., \& Klein, D. (2000). The influence of goal setting on exercise adherence. Journal of Health Education, 31, 277-281.

Cohen, E.A., Gelfand, D.M., Dodd, D.K., Jensen, J., \& Turner, C. (1980). Self-control practices associate with weight loss maintenance in children and adolescents. Behavior Therapy, 11(1), 26-37.

Cohen, J.A. (1992). A power primer. Psychological Bulletin, 112(1), 155-159.

Comrey, A. (1978). Common methodological problems in factor analytical studies. Journal of Clinical and Consulting Psychology, 46, 648-659. 
Cooper, M.D., \& Phillips, R.A. (2004). Exploratory analysis of the safety climate and safety behavior relationship. Journal of Safety Research, 35, 497-512.

Costello, A., \& Osborne, J. (2005). Best practices in exploratory factory analysis: Four recommendations for getting the most from your analysis. Practical Assessment, Research, and Evaluation, 10(7), 1-9.

Cronbach, L.J. (1951). Coefficiant alpha and the internal structure of tests. Psychometrika, 16(3), 297334.

Cronbach, L.J., \& Meehl, P. (1955). Construct validity in psychological tests. Psychological Bulletin, 52(4), 281-302.

Crump, C.E., Earp, J.L., Kozma, C.M., \& Hertz-Picciotto, I. (1996). Effect of organization-level variables on differential employee participation in 10 federal worksite health promotion programs. Health Education and Behavior, 23(2), 204-223.

Daniels, P., Noe, G.F., \& Mayberry, R. (2006). Barriers to prenatal care among black women of low socioeconomic status. American Journal of Health Behavior, 30(2), 188-198.

Davidson, P.L., \& Andersen, R.M., (1997). Determinants of dental care utilization for diverse ethnic and age groups. Advances in Dental Research, 11, 254-262.

De Ayala, R. J. (2009). The theory and practice of item response theory. New York, NY: Guilford Press

DeJoy, D.M., Bowen, H.M., Baker, K.M., Bynum, B.H., Wilson, M.G., Goetzel, R.Z., \& Dishman, R.K. (2009). Management support and worksite health promotion program effectiveness. Computer Science, 5624, 13-22.

Della, L.J., DeJoy, D.M., Goetzel, R.Z., Ozminkowski, R.J., \& Wilson, M.G. (2008). Assessing management support for worksite health promotion: Psychometric analysis of the Leading by Example (LBE) Instrument. American Journal of Health Promotion, 22(5), 359-367.

Denison, D.R. (1996). What is the difference between organizational culture and organizational 
climate? A native's point of view on a decade of paradigm wars. Academy of Management Review, 21(3), 619-654.

DeVellis, R. F. (2011). Scale development: Theory and applications. SAGE Publications, Thousand Oaks: CA.

Donnelly, J.E., Blair, S.N., Jakicic, J.M. (2009). Appropriate physical activity intervention strategies for weight loss and prevention of weight regain for adults. Medicine and Science in Sports and Exercise, 41(2), 459-471.

Ekvall, G. (1996). Organizational climate for creativity and innovation. European Journal of Work and Organizational Psychology, 5(1), 105-123.

Embretson, S.E., \& Reise, S.P. (2000). Item response theory for psychologists. Hillsdale, NJ: Earlbaum.

Emmons, K.M., Thompson, B., McLerran, D., Sorensen, G., Linnan, L., Basen-Engquist, K., \& Biener, L. (2000). The relationship between organizational characteristics and the adoption of workplace smoking policies. Health Education \& Behavior, 27(4), 483-501.

Emont, S.L., \& Cummings, K.M. (1990). Organizational factors affecting participation in a smoking cessation program and abstinence among 68 auto dealerships. American Journal of Health Promotion, 5, 107-114.

Employers' Resource Council. (2010). 2010 Northcoast 99 Report. Retrieved from http://www.northcoast99.com/reports/2010_NorthCoast_99_Winners_Report.pdf.

Faugier, J., \& Sargeant, M. (1997). Sampling hard to reach populations. Journal of Advanced Nursing, 26, 790-797.

Fava, J. L., \& Velicer, W. F. (1992). The effects of overextraction on factor and component analysis. Multivariate Behavior Research, 27, 387-415.

Finkelstein, E. A., Fiebelkorn, I. C., \& Wang, G. (2003). National medical spending attributable to overweight and obesity: how much, and who’s paying. Health Affairs, 3, 219-226. 
Fitzgerald, L.F., Drasgow, F., Hulin, C.L., Gelfand, M.J., \& Magley, V.J., (1997). Antecedents and consequences of sexual harassment in organizations: A test of an integrated model. Journal of Applied Psychology, 82, 587-589.

Flegal, K., Carroll, M. D., Ogden, C. L., \& Curtin, L. R. (2010). Prevalence and trends in obesity among U.S. adults, 1999-2008. Journal of the American Medical Association, 303(3), 235-241.

Fleiss J.L, (1981). Statistical Methods for Rates and Proportions. New York, NY: John Wiley \& Sons, Inc.

Fletcher, S.W., Morgan, T.M., O’Malley, M.S., Earp, J.A., \& Degnan, D. (1989). Is breast selfexamination predicted by knowledge, attitudes, beliefs, or sociodemographic characteristics? American Journal of Preventive Medicine, 5, 207-215.

Flin, R., Burns, C., Mearns, K., Yule, S., \& Robertson, E.M. (2006). Measuring safety climate in health care. Quality and Safety in Health Care, 15(2), 109-115.

Forehand, G.A., \& Gilmer, B. (1964). Environmental variation in studies of organizational behavior. Psychological Bulletin, 62, 361-382.

Garrow, J. S., \& Webster, J. (1985). Quetelet's index (W/H-2) as a measure of fatness. International Journal of Obesity, 9(2), 147-153.

Glick, W.H. (1985). Conceptualizing and measuring organizational and psychological climate: Pitfalls in multilevel research. The Academy of Management Review, 10, 601-616.

Guion, R.M., (1973). A note on organizational climate. Organizational Behavior and Human Performance, 9(1), 120-125.

Haines, P. S., Siega-Riz, A M., \& Popkin, B. M. (1999). The Diet Quality Index- Revised: A measurement instrument for populations. Journal of the American Dietetic Association, 99, 697704.

Hendrie, G., Cox, D., \& Coveney, J. (2008). Nutrition knowledge as a predictor of nutrient intake and diet quality. Journal of Nutrition Education and Behavior, 40(4), 50-51. 
Hertz, R. P., Unger, A. N., McDonald, M., Lustik, M. B., \& Biddulph-Krentar, J. (2004). The impact of obesity on work limitations and cardiovascular risk factors in the U.S. workforce. Journal of Occupational and Environmental Medicine, 46, 1196-1203.

Howze, E.H., Smith, M., \& DiGilio, D.A., (1989). Factors affecting the adoption of exercise behavior among sedentary older adults. Health Education Research, 4, 173-180.

Jackson, D.L., Gillaspy, J.A., \& Purc-Stephenson, R. (2009). Reporting practices in confirmatory factor analysis: An overview and some recommendations. Psychological Methods, 14(1), 6-23.

James, L.R. (1982). Aggregation bias in estimates of perceptual agreement. Journal of Applied Psychology, 67, 219-229.

Jeff, J.W. (1996). Linking employee perceptions of service climate to customer satisfaction. Personnel Psychology, 49(4), 831-851.

Jeffery, R.W., \& French, S.A. (1996). Socioeconomic status and weight control practices among 20to 45-year-old women. American Journal of Public Health, 86(7). 1005-1010.

Jones, A. P., \& James, L. R. (1979). Psychological climate: Dimensions and relationships of individual and aggregated work environment perceptions. Organizational Behavior and Human Performance, 23, 201-250.

Junqiao, W., Tanyun, L.V., Shoumei, J.I., Huifen, A., \& Hong, L. (2008). Knowledge level and performance of pelvic floor muscle exercise among aged women in community. Journal of Nursing Science, 20, 7-11.

Karasek, R., Gordon, G., Pietrokovsky, C., Frese, M., Pieper, C., Schwartz, J., Fry, L., \& Schirer, D. (1985). Job Content Instrument: Questionnaire and User's Guide. Loss Angeles: University of Southern California, Department of Industrial and Systems Engineering.

Kennedy, E. T., Ohls, F., Carlson, S., \& Fleming, K. (1995). The Healthy Eating Index: Design and applications. Journal of the American Dietetics Association, 95, 1103-1108. 
Klem, M.L., Wing, R.R., McGuire, M.T., Seagle, H.M., \& Hill, J.O. (1997), A descriptive study of individuals successful at long-term maintenance of substantial weight loss. The American Journal of Clinical Nutrition, 66, 239-246.

Kozlowski, S.W., \& Klein, K.J., (2000). A multilevel approach to theory and research in organizations: Contextual, temporal, and emergent processes. In Klein, K., Kozlowski, S. (Eds.), Multilevel theory, research, and methods in organizations: Foundations, extensions, and new directions (pp. 3-90). San Francisco, CA: Jossey-Bass.

Laiho, M., Honkala, E., Nyyssonen, V., \& Milen, A. (1991). Recall and perception of oral health education among 18-year-olds. Health Education Research, 6, 43-48.

Laitinen, J., Power, C., \& Järvelin, M. R. (2001). Family social class, maternal body mass index, childhood body mass index, and age at menarche as predictor of adult obesity. American Journal of Clinical Nutrition, 74, 287-294.

Landis, J.R., \& Koch, G.G. (1977). The measurement of observer agreement for categorical data. Biometrics, 33(1), 159-174.

Larson, E.L., Early, E., Cloonan, P., Sugrue, S., \& Parides, M. (2000). An organizational climate intervention associated with increased handwashing and decreased nosocomial infections. Behavioral Medicine, 26(1), 14-22.

Lewin, K., Lippitt, R., \& White, R.K. (1939). Patterns of aggressive behavior in experimentally created "social climates." Journal of Social Psychology, 10, 271-299.

Lewis, P. S., \& Malecha, A. (2011). The impact of workplace incivility on the work environment, manager skill, and productivity. Journal of Nursing Administration, 41, 41-47.

Litwin, G.H., \& Stringer, R.A., (1968). Motivation and organizational climate. Boston: Harvard University Press.

Luthans, F., Norman, S.M., Avolio, B.J., \& Avey, J.B. (2008). The mediating role of psychological 
capital in the supportive organizational climate-employee performance relationship. Journal of Organizational Behavior, 29, 219-238.

MacInnis, D.J., Moorman, C., \& Jaworski, B.J., (1991). Enhancing and measuring consumer's motivation, opportunity, and ability to process brand information from ads. Journal of Marketing, 56, 32-53.

Marsh, H. W., \& Hocevar, D. (1985). Application of confirmatory factor analysis to the study of self-concept: First- and higher-order factor models and their invariance across groups. Psychological Bulletin, 97, 562-582.

McLean, N., Griffin, S., Toney, K, \& Hardeman, W. (2003). Family involvement in weight control, weight maintenance, and weight-loss interventions: A systematic review of randomised trials. International Journal of Obesity, 27, 987-1005.

Mercer, A., \& Bilson, K. (1985). Factors influencing organizational commitment by physicians. Academy of Management Proceedings, 72-76.

Miller, W.C., Koceja, D.M., \& Hamilton, E.J. (1997). A meta-analysis of the past 25 years of weight loss research using diet, exercise, or diet plus exercise intervention. International Journal of Obesity, 21, 941-947.

Moorman, C. (1990). The effects of stimulus and consumer characteristics on the utilization of nutrition information. Journal of Consumer Research, 17, 362-374.

Moorman, C., \& Matulich, E. (1993). A model of consumers' preventive health behaviors: The role of health motivation and health ability. Journal of Consumer Research, 20, 208-228.

Moran, E.T., \& Volkwein, J.F. (1992). The cultural approach to the formation of organizational climate. Human Relations, 45, 19-47.

Neal, A., Griffin, M.A., \& Hart, P.M. (2000). The impact of organizational climate on safety climate and individual behavior. Safety Science, 34, 99-109. 
Neovius, K., Johansson, K., Kark, M., \& Neovius, M. (2008). Obesity status and sick leave: A systematic review. Obesity Reviews, 10(1), 17-27.

National Institute for Health and Clinical Excellence (NICE). (2008). Implementing NICE public bealth guidance for the workplace: A national organisational audit of NHS trusts in England.

Østbye, T., Dement, J.M., \& Krause, M.A. (2007). Obesity and workers' compensation: Results from the Duke Health and Safety Surveillance System. Archives of Internal Medicine, 167(8), 766-773.

Pate-Cornell, M.E., (1990). Organizational aspects of engineering system safety: The case of offshore platforms. Science, 30, 1210-1217.

Peterson, D.K. (2002). Deviant workplace behavior and the organization's ethical climate. Journal of Business and Psychology, 17(1), 47-61.

Podsakoff, P. M., MacKenzie, S. B., Lee, J. Y., \& Podsakoff, N. P. (2003). Common method biases in behavioral research: A critical review of the literature. Journal of Applied Psychology, 88, 879903.

Pollack, K. M., Sorock, G. S., Slade, M. D., Cantley, L., Sircar, K., Taiwo, O., et al. (2007). Association between body mass index and acute traumatic workplace injury in hourly manufacturing employees. American Journal of Epidemiology, 166(2), 204-211.

Pritchard, R.D., \& Karasick, B.W. (1971). The effects of organizational climate on managerial job performance and job satisfaction. Organizational Behavior and Human Performance, 9(1), 126146.

Poutanen, R., Lahti, S., \& Hausen, H. (2005). Oral health-related knowledge, attitudes, and beliefs among 11 to 12-year-old Finnish schoolchildren with different oral health behaviors. Acta Odontologica Scandinavica, 63(1), 10-16.

Raudenbush, S. W., \& Liu, X. (2000). Statistical power and optimal design for multisite randomized trials. Psychological Methods, 5, 199-213. 
Reichers, A.E., \& Schneider, B. (1990). Climate and culture: An evolution of constructs. In B. Schneider (Ed.), Organizational Climate and Culture, pp. 5-39. San Francisco, CA: Jossey-Bass.

Reise, S. P., Waller, N. G., \& Comrey, A. L. (2000). Factor analysis and scale revision. Psychological Assessment, 12, 287-297.

Reise, S. P., \& Yu, J. (1990). Parameter recovery in the graded response model using MULTILOG. Journal of Educational Measurements, 27, 133-144.

Ribisl, K.M., \& Reischl, T.M. (1993). Measuring the climate for health at organizations: Development of the worksite health climate scales. Journal of Occupational Medicine, 35(8), $812-824$.

Ricci, J. A., \& Chee, E. (2005). Lost productive time associated with excess weight in the U.S. workforce. Journal of Occupational and Environmental Medicine, 47, 1227-1234.

Robinson, S.L., \& Bennett, R.J., (1995). A typology of deviant workplace behaviors: A multidimensional scaling study. Academy of Management Joumal, 38(2), 555-572.

Rogg, K.L., Schmidt, D.B., Shull, C., \& Schmitt, N. (2001). Human resource practices, organizational climate, and customer satisfaction. Journal of Management, 27, 431-449.

Rost, K., Connell, C., Schechtman, K., Barzilai, B., \& Fisher, E.B. (1990). Predictors of employee involvement in a worksite health promotion program. Health Education Quarterly, 17, 395407.

Salanova, M., Agut, S., \& Peiro, J.M. (2005). Linking organizational resources and work engagement to employee performance and customer loyalty: The mediation of service climate. Joumal of Applied Psychology, 90(6), 1217-1227.

Salganik, M. J., \& Heckathorn, D. D. (2004). Sampling and estimation in hidden populations using respondent-driven sampling. Sociological Methodology, 34, 193-239.

Sallis, J.F., Grossman, R.M., Pinski, R.B., Patterson, T.L., \& Nader, P.R. (1987). The development of 
scales to measure social support for diet and exercise behaviors. Preventive Medicine, 16(6), 825-836.

Samejima, F. (1996). The graded response model. In: van der Linden, W.J., Hambleton, R. (Eds.) Handbook of modern item response theory (pp. 85-100). New York, NY: Springer.

Schneider, B. (1975). Organizational climates: An essay. Personnel Psychology, 28(4), 447-479.

Schneider, B., White, S.S., \& Paul, M.C. (1998). Linking service climate and customer perceptions of service quality. Journal of Applied Psychology, 83

Scott, K. M., McGee, M. A., Wells, J. E., \& Browne, M. A. (2008). Obesity and mental disorders in the adult general population. Journal of Psychosomatic Research, 64(1), 97-105.

Shannon, H.S., Mayr, J., \& Haines, T. (1998). Overview of the relationship between organizational and workplace factors and injury rates. Safety Science, 26, 201-217.

Sloan, R.P., \& Gruman, J.C. (1988). Participation in workplace health promotion programs: The contribution of health and organizational factors. Health Education Quarterly, 15, 269-288.

Smith, R.E., Smoll, F.L., \& Cumming, S.P. (2007). Effects of a motivational climate intervention for coaches on young athletes' sport performance anxiety. Journal of Sport and Exercise Psychology, 29(1), 39-59.

Sorensen, G., Linnan, L., \& Hunt, M.K. (2004). Worksite-based research and initiatives to increase fruit and vegetable consumption. Preventive Medicine, 39(2), 94-100.

Spector, P.E., \& Jex, S.M., (1998). Development of four self-report measures of job stressors and strain: Interpersonal Conflict at Work Scale, Organizational Constraints Scale, Quantitative Workload Inventory, and Physical Symptoms Inventory. Journal of Occupational Health Psychology, 3(4), 356-367.

Speers, M.A., Niemcryk, S.J., Morter, R., Gary, H.E., \& Ostfeld, A.M., (1990). Spouse similarities in high blood pressure knowledge: Implications for control of high blood pressure. American 
Journal of Preventive Medicine, 6, 20-27.

Stark, S. (2001). MODFIT: A computer program for model-data fit. Champaign, IL: University of Illinois at Urbana-Champaign.

Streiner, D. L. (1994). Figuring our factors: The use and misuse of factor analysis. Canadian Journal of Psychiatry, 39, 135-140.

Thissen, D. (1986). MULTILOG version 5 users' guide. Mooresville, IN: Scientific Software, Inc.

Thomas, E.J., Sexton, J.B., Neilands, T.B., Frankel, A., \& Helmreich, R.L. (2005). The effect of executive walk rounds on nurse safety climate attitudes: A randomized trial of clinical units. BMC Health Sercice Research, 5, 28-36.

Trevino, L.K., Butterfield, K.D., \& McCabe, D.L. (2001). The ethical context in organizations: Influences on employee attitudes and behaviors. Research in Ethical Issues in Organizations, 3, 301-337.

Troumbley, P., \& Lenz, E. (1992). Application of Cox's interaction model of client health behavior in a weight control program for military personnel: A preintervention baseline. Advances in Nursing Science, 14, 65-78.

Trudeau, E., Kristal, A., Li, S., \& Patterson, R. (1998). Demographic and psychosocial predictors of fruit and vegetable intakes differ: Implications for dietary interventions. Journal of American Dietetic Association, 98, 1412-1417.

van den Hooff, B., \& de Ridder, J.A. (2004). Knowledge sharing in context: The influence of organizational commitment, communication climate, and CMC use on knowledge sharing. Journal of Knowledge Management, 8(6), 117-130.

Verbeke, W., Volgering, M., \& Hessels, M. (1998). Exploring the conceptual expansion within the field of organizational behaviour: Organizational climate and organizational culture. Journal of Management Studies, 35, 303-329. 
Wang, Y., Beydoun, M.A., Lian, L., Caballero, B., \& Kumanyika, S.K. (2007). Will all Americans become overweight or obese? Estimating the progression and cost of the U.S. obesity epidemic. Obesity, 16(10), 2323-2330.

Williamson, A.M., Feyer, A.M., Cairns, D., \& Biancotti, D. (1997). The development of a measure of safety climate: The role of safety perceptions and attitudes. Safety Science, 25, 15-27.

Wolford, K.A., Sliter, M.T., Jex, S., \& Withrow, S. (n.d.) Personal and organizational correlates of employee obesity: An examination of sex and physical activity as moderators. Unpublished manuscript.

Wood, J. M., Tataryn, D. J., \& Gorsuch, R. L. (1996). Effects of under- and overextraction on principal axis factor analysis with varimax rotation. Psychological Methods, 1, 354-365.

Wynia, M.K, Johnson, M., McCoy, T.P., Griffin, L.P., \& Osborn, C.Y. (2010). Validation of an organizational communication climate assessment toolkit. American Journal of Medical Quality, 25(5), $1-8$.

Yancey, A. K., Cochran, S. D., Corliss, H. L., \& Mays, V. M. (2003). Correlates of overweight and obesity among lesbian and bisexual women. Preventative Medicine, 36, 1-8.

Yeh, C.W. (2009). Service climate, professional commitment, and job performance of flight attendants in Taiwan. Journal of Air Transport Management, 15(5), 259-260. 
Zohar, D. (2000). A group-level model of safety climate. Journal of Applied Psychology, 85(4), 587-596.

Zohar, D. (2005). A multilevel model of safety climate: Cross-level relationships between organization and group-level climates. Journal of Applied Psychology, 90(4), 616-628.

Zweig, S., LeFrevre, M., \& Kruse, J. (1988). The health belief model and attendance for prenatal care. Family Practitioner Research Journal, 8(1), 32-41. 
Table 1: Items and factor loadings from exploratory factor analyses.

\begin{tabular}{|c|c|c|c|c|}
\hline \multirow[b]{2}{*}{ Factors and Items } & \multicolumn{4}{|c|}{ Factor Loadings } \\
\hline & 1 & 2 & 3 & 4 \\
\hline \multicolumn{5}{|l|}{ 1. General organizational support } \\
\hline $\begin{array}{l}\text { My organization actively promotes maintenance of a healthy } \\
\text { weight }\end{array}$ & .85 & .15 & .21 & .09 \\
\hline $\begin{array}{l}\text { My organization does more to promote healthy weight than } \\
\text { other organizations I know }\end{array}$ & .82 & .16 & .23 & .08 \\
\hline $\begin{array}{l}\text { My organization truly cares about helping individuals stay fit } \\
\text { and healthy }\end{array}$ & .81 & .14 & .24 & .18 \\
\hline $\begin{array}{l}\text { My organization provides information about how } \\
\text { maintenance of a healthy weight is beneficial }\end{array}$ & .79 & .08 & .13 & .07 \\
\hline $\begin{array}{l}\text { My organization's policies make it easier for me to maintain } \\
\text { a healthy weight }\end{array}$ & .72 & .26 & .13 & .11 \\
\hline $\begin{array}{l}\text { My organization is innovative in promoting healthy weight } \\
\text { among employees }\end{array}$ & .72 & .11 & .26 & .04 \\
\hline $\begin{array}{l}\text { Managers in my organization seem to really value employee } \\
\text { health and fitness }\end{array}$ & .69 & .22 & .27 & .16 \\
\hline $\begin{array}{l}\text { Managers in my organization encourage participation in } \\
\text { weight maintenance programs }\end{array}$ & .48 & .08 & .28 & .07 \\
\hline \multicolumn{5}{|l|}{ 2. Healthy diet norms } \\
\hline My coworkers often encourage unhealthy food choices & .07 & .70 & .08 & .10 \\
\hline $\begin{array}{l}\text { It is common for my coworkers to have candy or other little } \\
\text { treats available }\end{array}$ & .10 & .69 & .06 & -.06 \\
\hline $\begin{array}{l}\text { When my coworkers bring food to the workplace, it tends } \\
\text { to be sugary or fattening }\end{array}$ & .14 & .65 & .16 & .07 \\
\hline My coworkers commonly snack while working & .13 & .60 & -.03 & .00 \\
\hline $\begin{array}{l}\text { Managers at my organization often provide unhealthy } \\
\text { snacks to employees }\end{array}$ & .16 & .59 & -.04 & .13 \\
\hline $\begin{array}{l}\text { My coworkers more likely to choose fast food for lunch } \\
\text { than to bring healthy meals from home }\end{array}$ & .11 & .53 & .26 & .01 \\
\hline \multicolumn{5}{|l|}{ 3. Social support for healthy weight } \\
\hline My coworkers discuss ways to maintain a healthy weight & .13 & -.06 & .67 & .12 \\
\hline
\end{tabular}


Most of my coworkers are actively trying to maintain a healthy weight

My coworkers are more committed to maintaining a healthy weight than people I know in other organizations

$\begin{array}{llll}.27 & .29 & .57 & -.03\end{array}$

If I started a new weight loss program, I know I could count on my coworkers for support

$\begin{array}{llll}.17 & .12 & .55 & -.13\end{array}$

I often notice my coworkers taking small steps to stay active (taking the stairs instead of the elevator, parking further

My coworkers recognize one another for reaching and maintaining weight goals

4. Belittling and distrusting behavior

If I participated in a company weight loss program, I'd be worried about being made fun of by the managers

I'd be worried about being made fun of by my coworkers if I participated in a company weight loss program 
Table 2. Items and parameters estimates from item response theory analyses.

\begin{tabular}{|c|c|c|c|c|c|c|c|}
\hline \multirow[b]{2}{*}{ Factors and Items } & \multicolumn{5}{|c|}{ Item Parameters } & \multicolumn{2}{|c|}{ Information } \\
\hline & $\alpha$ & $\beta 1$ & $\beta 2$ & $\beta 3$ & $\beta 4$ & $\theta$ & Value \\
\hline \multicolumn{8}{|l|}{ General organizational support } \\
\hline $\begin{array}{l}\text { My organization actively promotes maintenance of a healthy } \\
\text { weight }\end{array}$ & 4.54 & -1.34 & -0.33 & 0.27 & 1.18 & -0.40 & 5.25 \\
\hline $\begin{array}{l}\text { My organization does more to promote healthy weight than } \\
\text { other organizations I know }\end{array}$ & 3.78 & -0.99 & -0.19 & 0.56 & 1.32 & 0.60 & 3.91 \\
\hline $\begin{array}{l}\text { My organization truly cares about helping individuals stay fit and } \\
\text { healthy }\end{array}$ & 4.26 & -1.44 & -0.43 & 0.36 & 1.20 & 1.20 & 4.65 \\
\hline $\begin{array}{l}\text { My organization provides information about how maintenance } \\
\text { of a healthy weight is beneficial }\end{array}$ & 2.75 & -1.56 & -0.53 & 0.42 & 1.56 & 0.20 & 2.07 \\
\hline $\begin{array}{l}\text { My organization's policies make it easier for me to maintain a } \\
\text { healthy weight }\end{array}$ & 2.83 & -1.55 & -0.37 & 0.66 & 1.69 & 0.60 & 2.18 \\
\hline $\begin{array}{l}\text { My organization is innovative in promoting healthy weight } \\
\text { among employees }\end{array}$ & 1.46 & -1.51 & -0.38 & 0.65 & 2.02 & 0.00 & 0.47 \\
\hline $\begin{array}{l}\text { Managers in my organization seem to really value employee } \\
\text { health and fitness }\end{array}$ & 2.94 & -1.20 & -0.23 & 0.18 & 1.30 & 0.00 & 2.61 \\
\hline $\begin{array}{l}\text { Managers in my organization encourage participation in weight } \\
\text { maintenance programs }\end{array}$ & 1.23 & -1.58 & -0.07 & 0.99 & 2.43 & 0.20 & 0.65 \\
\hline \multicolumn{8}{|l|}{ Healthy diet norms } \\
\hline My coworkers often encourage unhealthy food choices & 2.43 & -1.26 & 0.38 & 1.20 & 2.57 & 0.80 & 2.65 \\
\hline $\begin{array}{l}\text { It is common for my coworkers to have candy or other little } \\
\text { treats available }\end{array}$ & 2.38 & -1.69 & -0.46 & 0.61 & 2.31 & -0.60 & 2.98 \\
\hline $\begin{array}{l}\text { When my coworkers bring food to the workplace, it tends to be } \\
\text { sugary or fattening }\end{array}$ & 2.22 & -1.13 & -0.29 & 1.10 & 2.45 & 0.20 & 2.45 \\
\hline
\end{tabular}




\begin{tabular}{|c|c|c|c|c|c|c|c|}
\hline My coworkers do not usually snack while working & 1.98 & -0.89 & 0.73 & 1.28 & 2.48 & 1.20 & 1.38 \\
\hline $\begin{array}{l}\text { Managers in my organization often provide unhealthy snacks to } \\
\text { employees }\end{array}$ & 1.81 & -1.71 & -0.15 & 0.65 & 2.36 & 0.20 & 0.98 \\
\hline $\begin{array}{l}\text { My coworkers more likely to choose fast food for lunch than to } \\
\text { bring healthy meals from home }\end{array}$ & 1.51 & -0.80 & 1.05 & 1.60 & 3.31 & 1.40 & 0.59 \\
\hline \multicolumn{8}{|l|}{ Social support for healthy weight } \\
\hline My coworkers discuss ways to maintain a healthy weight & 2.59 & -2.12 & -0.85 & 0.01 & 0.96 & 0.00 & 2.71 \\
\hline $\begin{array}{l}\text { Most of my coworkers are actively trying to maintain a healthy } \\
\text { weight }\end{array}$ & 1.90 & -1.85 & -0.51 & 0.54 & 1.89 & 0.20 & 1.10 \\
\hline $\begin{array}{l}\text { My coworkers are more committed to maintaining a healthy } \\
\text { weight than people I know in other organizations }\end{array}$ & 1.95 & -2.06 & -0.99 & -0.01 & 1.66 & 1.00 & 1.44 \\
\hline $\begin{array}{l}\text { If I started a new weight loss program, I know I could count on } \\
\text { my coworkers for support }\end{array}$ & 5.80 & -2.84 & -1.71 & -1.29 & 0.02 & -1.40 & 8.23 \\
\hline $\begin{array}{l}\text { I often notice my coworkers taking small steps to stay active } \\
\text { (taking the stairs instead of the elevator, parking further from the } \\
\text { door) }\end{array}$ & 0.98 & -1.63 & 0.13 & 1.14 & 2.93 & 0.40 & .70 \\
\hline $\begin{array}{l}\text { My coworkers recognize one another for reaching and } \\
\text { maintaining weight goals }\end{array}$ & 1.53 & -3.37 & -1.25 & 0.08 & 2.63 & -.80 & 1.99 \\
\hline \multicolumn{8}{|l|}{ Belittling and distrusting behavior } \\
\hline $\begin{array}{l}\text { If I participated in a company weight loss program, I'd be } \\
\text { worried about being made fun of by the managers }\end{array}$ & 1.33 & -3.29 & -1.32 & -0.64 & 1.24 & -1.40 & 0.42 \\
\hline $\begin{array}{l}\text { I'd be worried about being made fun of by my coworkers if I } \\
\text { participated in a company weight loss program }\end{array}$ & 1.35 & -3.68 & -2.51 & -0.04 & 1.30 & -2.20 & 0.39 \\
\hline
\end{tabular}


Managers in my organization think that weight maintenance programs are pointless

If my organization were to start a new weight loss promotion program, I'd assume it was only for show

Information columns display the point at which information is maximal $(\theta)$ and the information value at this point (value)

Highlighted items were retained for Stage 3 
Table 3: Demographics by organization.

\begin{tabular}{|c|c|c|c|c|c|c|c|c|}
\hline \multirow[b]{2}{*}{ Organization } & \multirow[b]{2}{*}{$n$} & \multirow[b]{2}{*}{ State } & \multirow{2}{*}{$\begin{array}{c}\text { Sex } \\
\% \text { Male }\end{array}$} & \multirow{2}{*}{$\begin{array}{c}\text { Race } \\
\% \text { White }\end{array}$} & \multicolumn{2}{|c|}{ Age } & \multicolumn{2}{|c|}{ Tenure } \\
\hline & & & & & $M$ & $s$ & $M$ & $s$ \\
\hline 1 & 17 & $\mathrm{KY}$ & 76.47 & 82.35 & 32.40 & 9.91 & 4.67 & 1.66 \\
\hline 2 & 16 & KY & 93.75 & 100.00 & 41.26 & 6.48 & 5.49 & 2.88 \\
\hline 3 & 19 & $\mathrm{OH}$ & 15.79 & 89.47 & 34.08 & 4.67 & 7.61 & 4.90 \\
\hline 4 & 12 & MI & 58.33 & 50.00 & 26.29 & 3.11 & 1.51 & 1.90 \\
\hline 5 & 12 & $\mathrm{CA}$ & 41.67 & 66.67 & 38.84 & 8.20 & 5.08 & 2.33 \\
\hline 6 & 15 & $\mathrm{IN}$ & 66.67 & 80.00 & 30.42 & 5.00 & 2.14 & 1.62 \\
\hline 7 & 13 & $\mathrm{OH}$ & 61.54 & 84.62 & 32.63 & 4.27 & 2.54 & 1.99 \\
\hline 8 & 11 & $\mathrm{OH}$ & 45.45 & 100.00 & 39.58 & 8.02 & 3.15 & 2.02 \\
\hline 9 & 10 & KY & 70.00 & 90.00 & 32.24 & 3.40 & 1.71 & 1.06 \\
\hline 10 & 19 & GA & 84.21 & 52.63 & 29.76 & 4.51 & 1.30 & 0.88 \\
\hline 11 & 10 & $\mathrm{NH}$ & 10.00 & 100.00 & 34.38 & 6.19 & 2.36 & 1.29 \\
\hline 12 & 10 & $\mathrm{AR}$ & 50.00 & 80.00 & 28.37 & 3.75 & 1.70 & 1.00 \\
\hline 13 & 9 & MI & 77.78 & 44.40 & 31.31 & 4.82 & 3.31 & 2.13 \\
\hline 14 & 11 & $\mathrm{OH}$ & 45.45 & 100.00 & 36.65 & 5.53 & 5.16 & 2.95 \\
\hline 15 & 17 & KY & 47.06 & 76.47 & 33.00 & 3.06 & 1.88 & 1.02 \\
\hline 16 & 18 & KY & 61.11 & 50.00 & 38.20 & 5.53 & 3.67 & 1.94 \\
\hline 17 & 13 & FL & 69.23 & 84.62 & 37.34 & 4.23 & 2.34 & 1.21 \\
\hline 18 & 14 & $\mathrm{OH}$ & 42.86 & 100.00 & 32.04 & 6.29 & 3.14 & 1.77 \\
\hline 19 & 16 & $\mathrm{KY}$ & 43.75 & 81.25 & 28.68 & 2.85 & 2.20 & 1.46 \\
\hline 20 & 17 & $\mathrm{TX}$ & 52.94 & 70.59 & 32.94 & 5.22 & 3.27 & 2.25 \\
\hline 21 & 9 & $\mathrm{CO}$ & 66.66 & 100.00 & 41.53 & 2.23 & 8.31 & 3.65 \\
\hline 22 & 10 & KY & 100.00 & 90.00 & 29.57 & 4.15 & 1.69 & 0.63 \\
\hline 23 & 17 & VA & 58.82 & 94.12 & 30.16 & 3.78 & 2.24 & 1.15 \\
\hline 24 & 15 & NY & 33.33 & 86.67 & 42.23 & 5.64 & 5.16 & 3.08 \\
\hline 25 & 12 & KY & 8.33 & 83.33 & 26.22 & 3.18 & 2.08 & 1.41 \\
\hline 26 & 18 & CA & 55.55 & 88.89 & 35.72 & 4.48 & 3.34 & 2.05 \\
\hline
\end{tabular}


Table 4: Predicted direction and strength of convergent and discriminant validity correlations

\begin{tabular}{|c|c|c|c|}
\hline \multirow[b]{2}{*}{ Variable } & \multicolumn{2}{|c|}{ Relationship with New Scale } & \multirow[b]{2}{*}{ Supported } \\
\hline & Direction & Strength & \\
\hline Physical Activity & + & Moderate & Yes \\
\hline Diet Quality & + & Moderate & Yes \\
\hline Health Motivation & + & Moderate & Yes \\
\hline Health Knowledge (Diet-related) & + & Weak & Yes \\
\hline General Health Symptoms & - & Weak & Yes \\
\hline Body Mass Index & - & Moderate & No \\
\hline Worksite Incentives for Health & + & Moderate & No \\
\hline Leadership Support for Health & + & Moderate & No \\
\hline Existing Health Climate Measure & + & Strong & Yes \\
\hline Social Support for Exercise & + & Moderate & $\mathrm{No}$ \\
\hline
\end{tabular}


Table 5:Confirmatory factor analysis fit indices

\begin{tabular}{|c|c|c|c|c|c|c|}
\hline Model & $x^{2}$ & $x^{2} / d f$ & RMSEA & NFI & $\mathrm{CFI}$ & $d f$ \\
\hline Main & 229.59 & 3.10 & .08 & .90 & .87 & 74 \\
\hline Alternate 1 & 229.59 & 3.10 & .12 & .78 & .79 & 74 \\
\hline Alternate 2 & 809.27 & 10.51 & .21 & .63 & .65 & 77 \\
\hline Independence & 2203.60 & 24.22 & .33 & .00 & .17 & 91 \\
\hline
\end{tabular}


Table 6: Mean item response, standard deviation, and correlations among study variables.

\begin{tabular}{|c|c|c|c|c|c|c|c|c|c|c|c|c|c|c|c|c|c|c|c|c|}
\hline Measures & $M$ & $s$ & 1 & 2 & 3 & 4 & 5 & 6 & 7 & 8 & 9 & 10 & 11 & 12 & 13 & 14 & 15 & 16 & 17 & 18 \\
\hline \multicolumn{21}{|l|}{ New climate scale } \\
\hline 1. Composite & 2.99 & .83 & .86 & - & - & - & - & - & - & - & - & - & - & - & - & - & - & - & - & - \\
\hline 2. Organizational support & 3.10 & 1.29 & .87 & .92 & - & - & - & - & - & - & - & - & - & - & - & - & - & - & - & - \\
\hline 3. Healthy diet norms & 2.36 & .94 & .67 & .29 & .83 & - & - & - & - & - & - & - & - & - & - & - & - & - & - & - \\
\hline 4. Social support & 3.41 & .90 & .81 & .56 & .32 & .84 & - & - & - & - & - & - & - & - & - & - & - & - & - & - \\
\hline \multicolumn{21}{|l|}{ Existing climate scales } \\
\hline 5. Workplace health support & 3.16 & 1.18 & .54 & .71 & .16 & .41 & .88 & - & - & - & - & - & - & - & - & - & - & - & - & - \\
\hline 6. Leadership health support & 2.64 & 1.12 & .59 & .72 & .23 & .34 & .71 & .84 & - & - & - & - & - & - & - & - & - & - & - & - \\
\hline 7. General health climate & 2.60 & .73 & .62 & .56 & .26 & .55 & .48 & .54 & .65 & - & - & - & - & - & - & - & - & - & - & - \\
\hline 8. Exercise social support & 2.78 & 1.16 & .51 & .47 & .11 & .67 & .45 & .35 & .60 & .89 & - & - & - & - & - & - & - & - & - & - \\
\hline \multicolumn{21}{|l|}{ Health-related scales } \\
\hline 9. Health motivation & 3.67 & .94 & .34 & .33 & .18 & .31 & .30 & .25 & .25 & .22 & .92 & - & - & - & - & - & - & - & - & - \\
\hline 10. Health knowledge (diet) & 7.12 & 2.76 & .13 & .06 & .03 & .25 & .12 & -.06 & .11 & .12 & .46 & .81 & - & - & - & - & - & - & - & - \\
\hline 11. Physical symptoms & 1.31 & .18 & -.26 & -.22 & -.26 & -.13 & -.11 & -.10 & -.16 & -.11 & -.25 & -.13 & .66 & - & - & - & - & - & - & - \\
\hline 12. Diet quality & 4.41 & .94 & .39 & .39 & .45 & .24 & .36 & .26 & .31 & .37 & .56 & .36 & -.38 & .84 & - & - & - & - & - & - \\
\hline 13. Physical activity level & 2.67 & .80 & .39 & .29 & .36 & .29 & .28 & .27 & .28 & .35 & .25 & .01 & -.33 & .38 & .65 & - & - & - & - & - \\
\hline 14. Body mass index (BMI) & 25.78 & 5.60 & -.18 & -.16 & -.21 & -.13 & -.09 & -.09 & -.03 & .09 & -.17 & -.04 & .22 & -.07 & -.28 & - & - & - & - & - \\
\hline \multicolumn{21}{|l|}{ Demographic variables } \\
\hline 15. Sex & 1.69 & .46 & .05 & .03 & -.05 & .12 & .08 & -.04 & -.02 & .03 & .33 & .24 & -.06 & .20 & .00 & -.03 & - & - & - & - \\
\hline 16. Age & 36.05 & 10.98 & -.06 & -.08 & -.01 & -.02 & .03 & .00 & .02 & -.05 & -.07 & -.07 & .13 & .01 & -.21 & .12 & -.12 & - & - & - \\
\hline 17. Race & 1.15 & .36 & -.09 & -.10 & .03 & -.12 & -.18 & -.05 & -.18 & -.04 & -.11 & -.09 & -.02 & -.12 & -.03 & .01 & -.14 & -.08 & - & - \\
\hline 18. Tenure & 6.00 & 6.39 & .00 & .03 & .04 & -.07 & .08 & -.09 & -.03 & -.11 & -.12 & -.04 & .18 & -.01 & -.15 & .10 & -.03 & .52 & -.06 & - \\
\hline
\end{tabular}

Correlations of $+/-.13$ or higher are significant at $p<.05$

Correlations of $+/-.17$ or higher are significant at $p<.01$

Scale reliabilities shown in italics on diagonals (not shown for single item measures)

Health knowledge score is average number of items correctly answered 
Figure 1: Overall test information for organizational support subscale

Test Information and Measurement Error

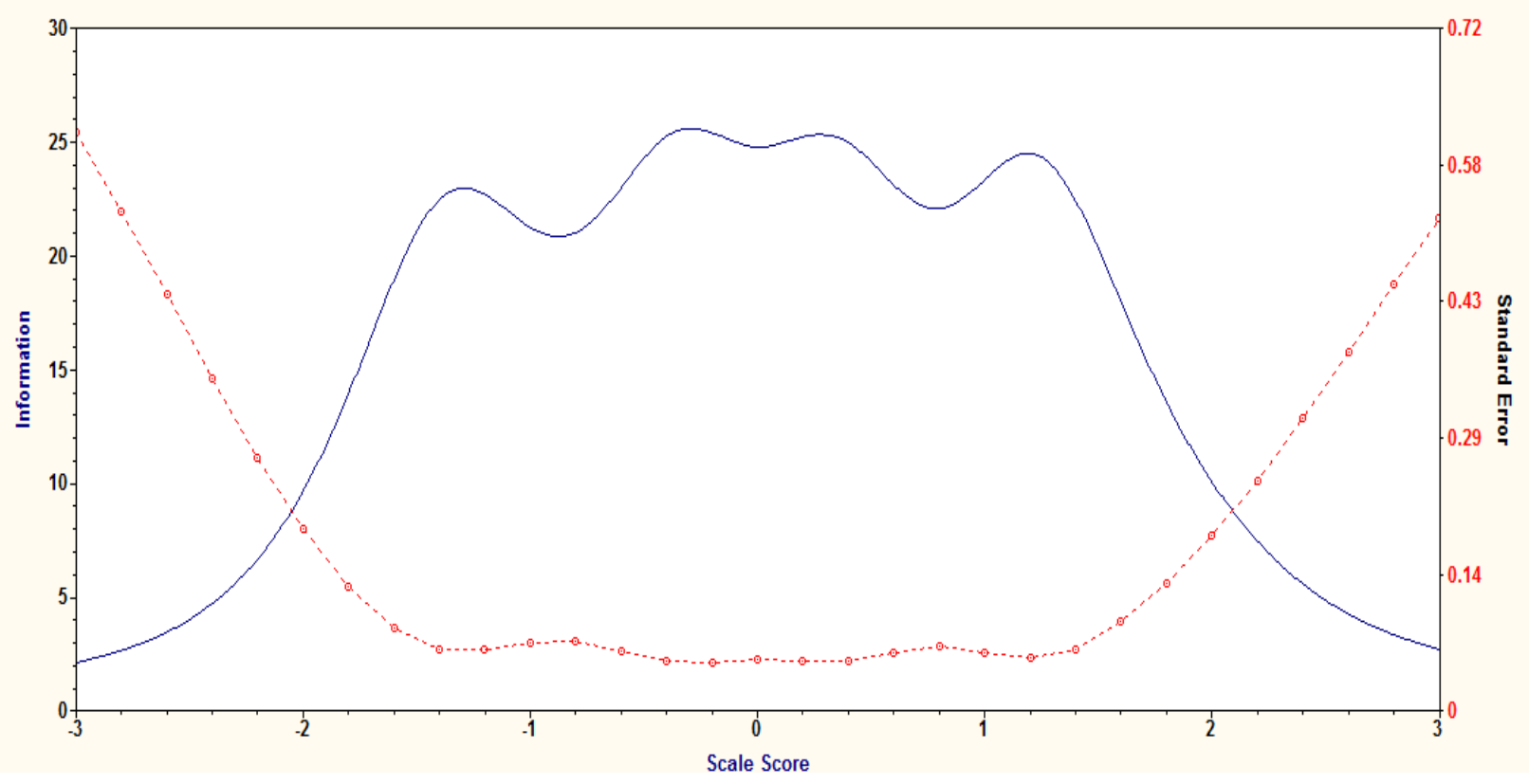


Figure 2: Overall test information for diet norms subscale

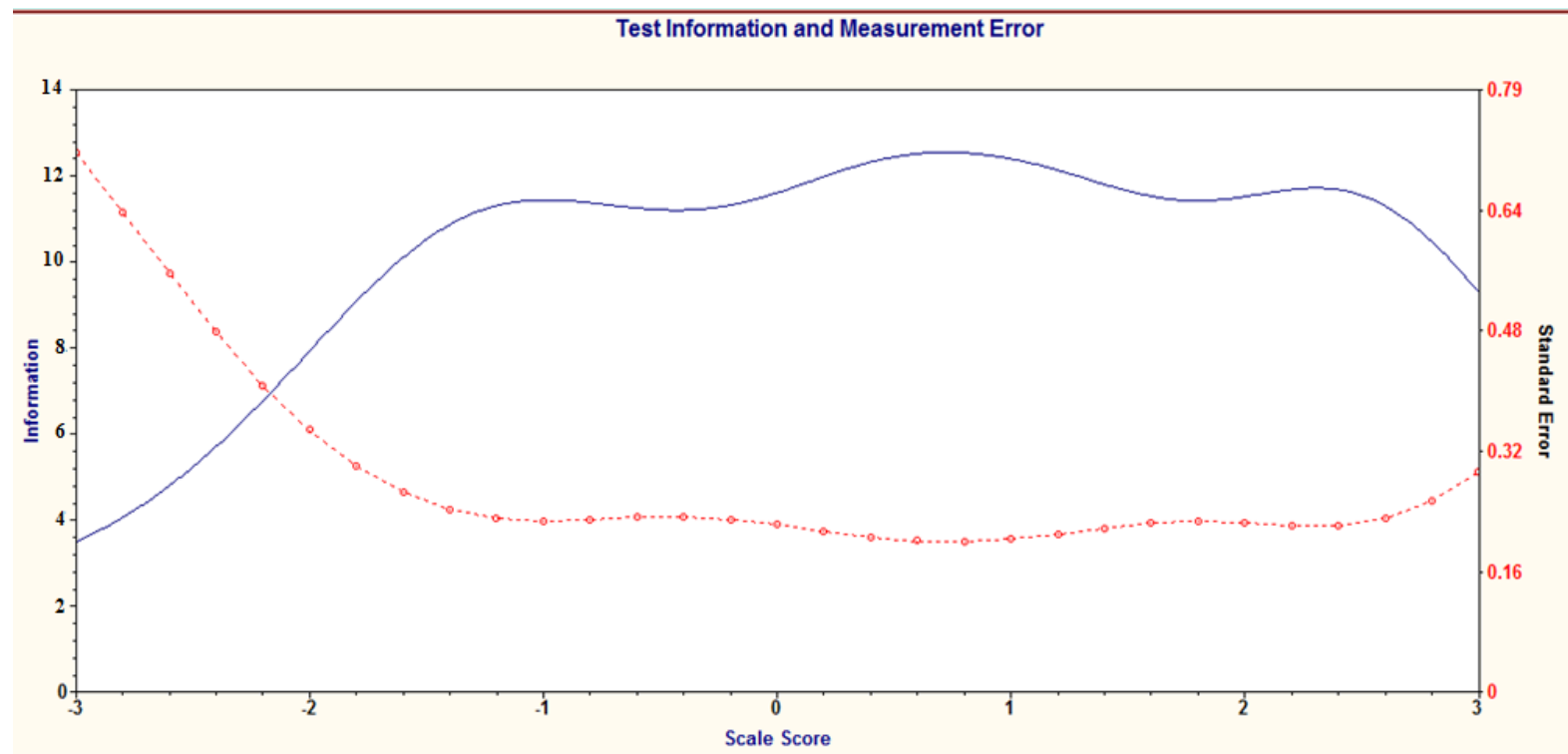


Figure 3: Overall test information for social support for healthy weight maintenance subscale

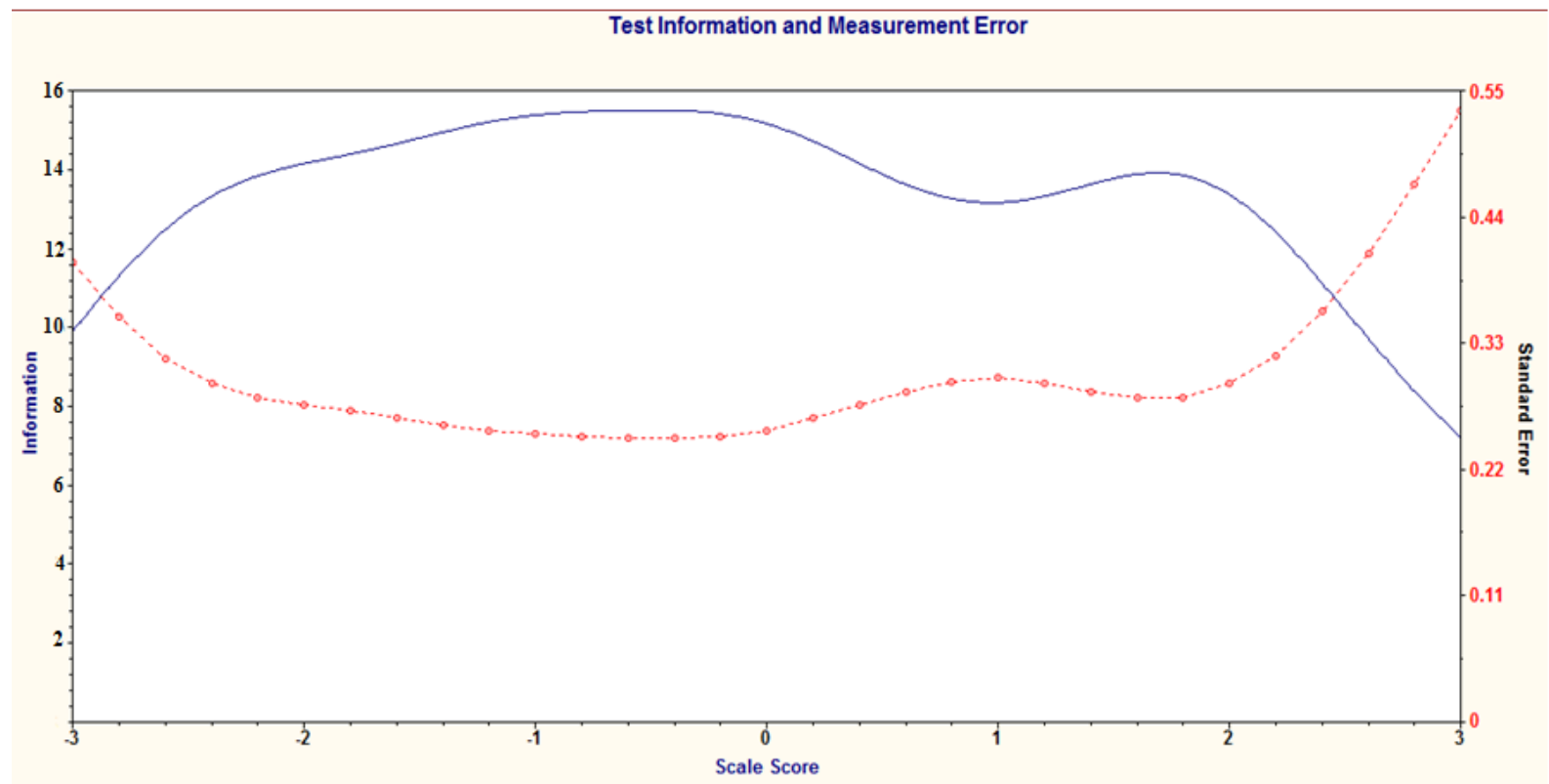


Figure 4: Overall test information for belittling and distrusting behavior subscale

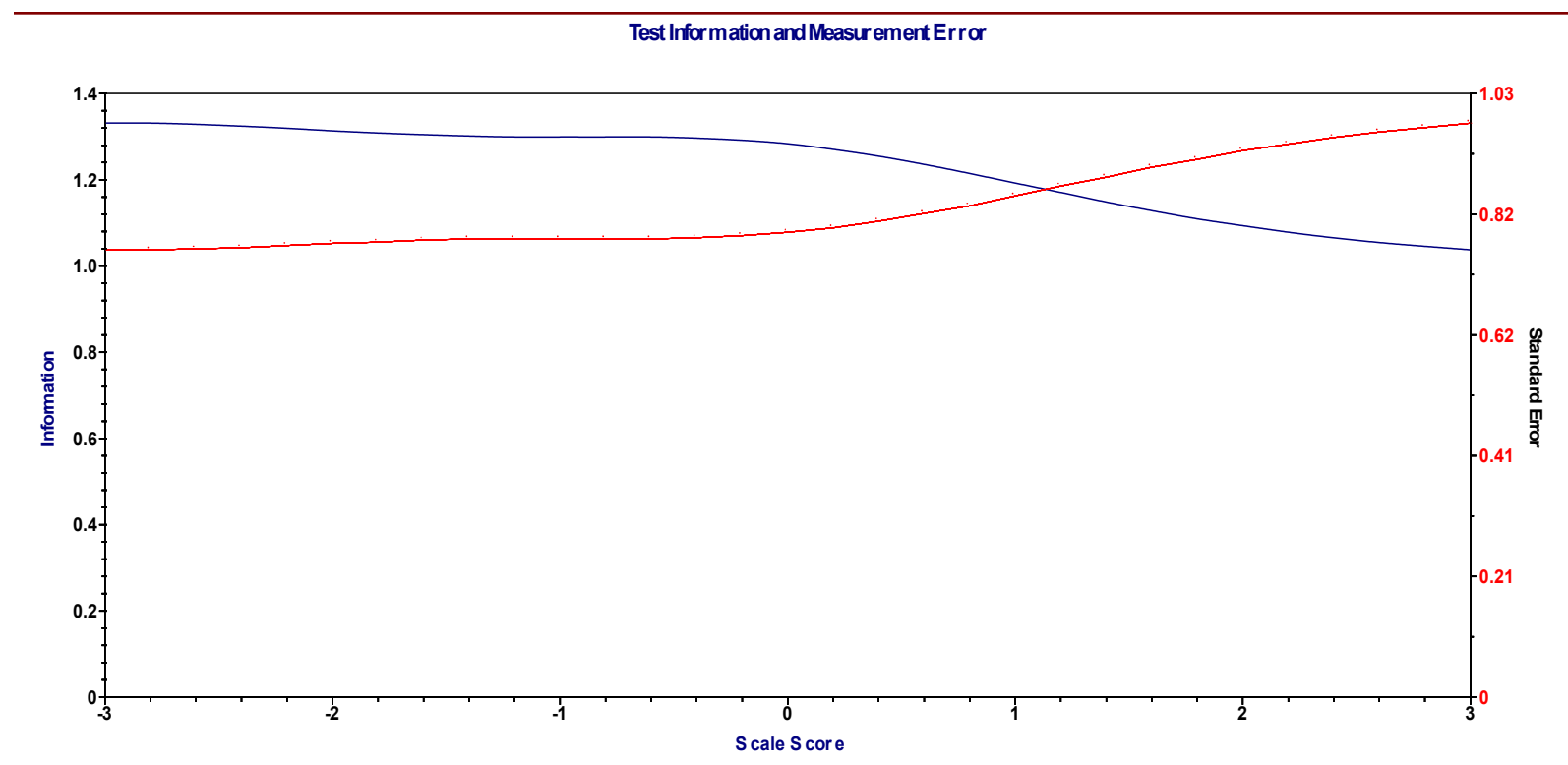


Figure 5: Representative item-level information plot for belittling and distrusting behavior subscale

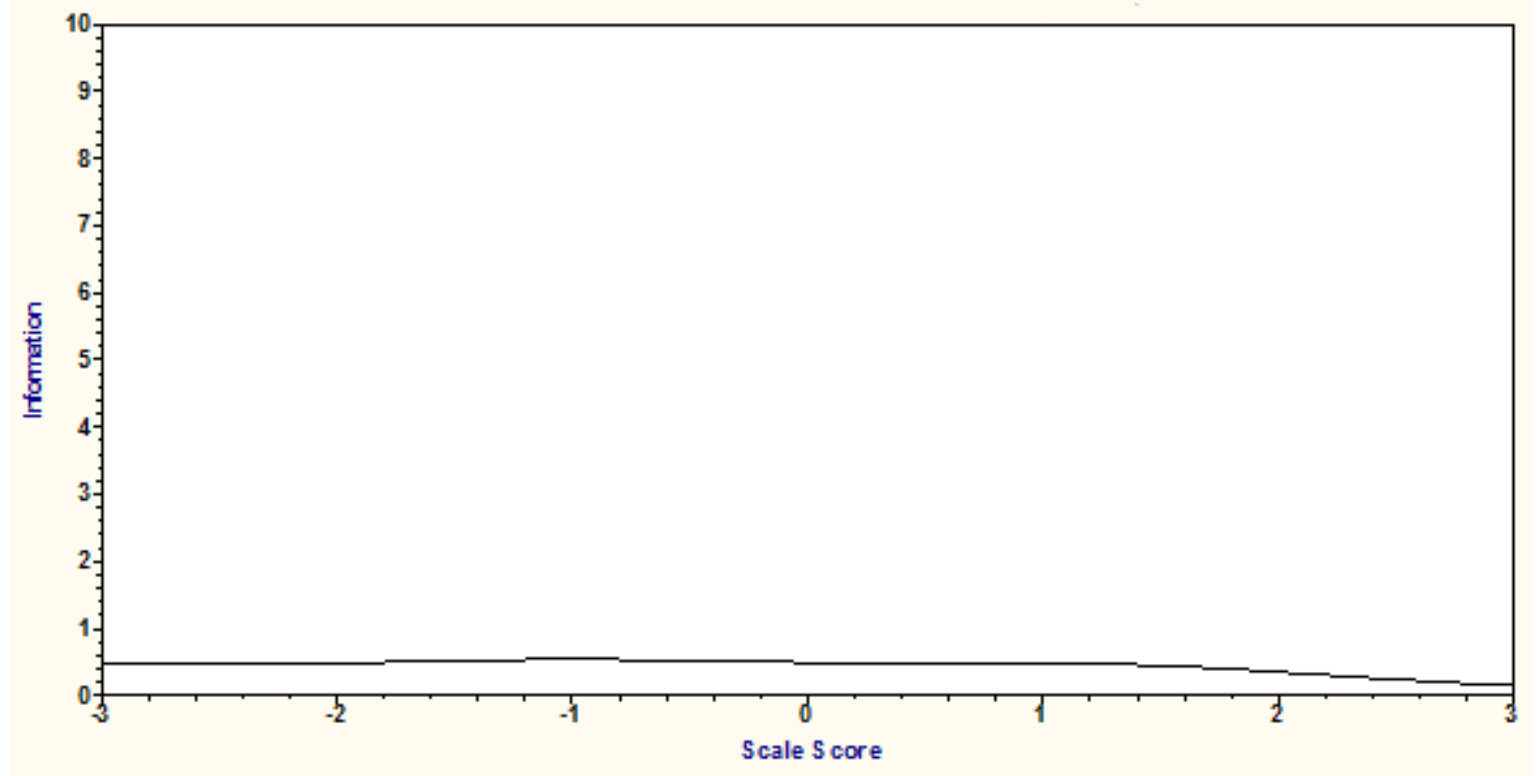


Figure 6: Standardized results of confirmatory factor analysis

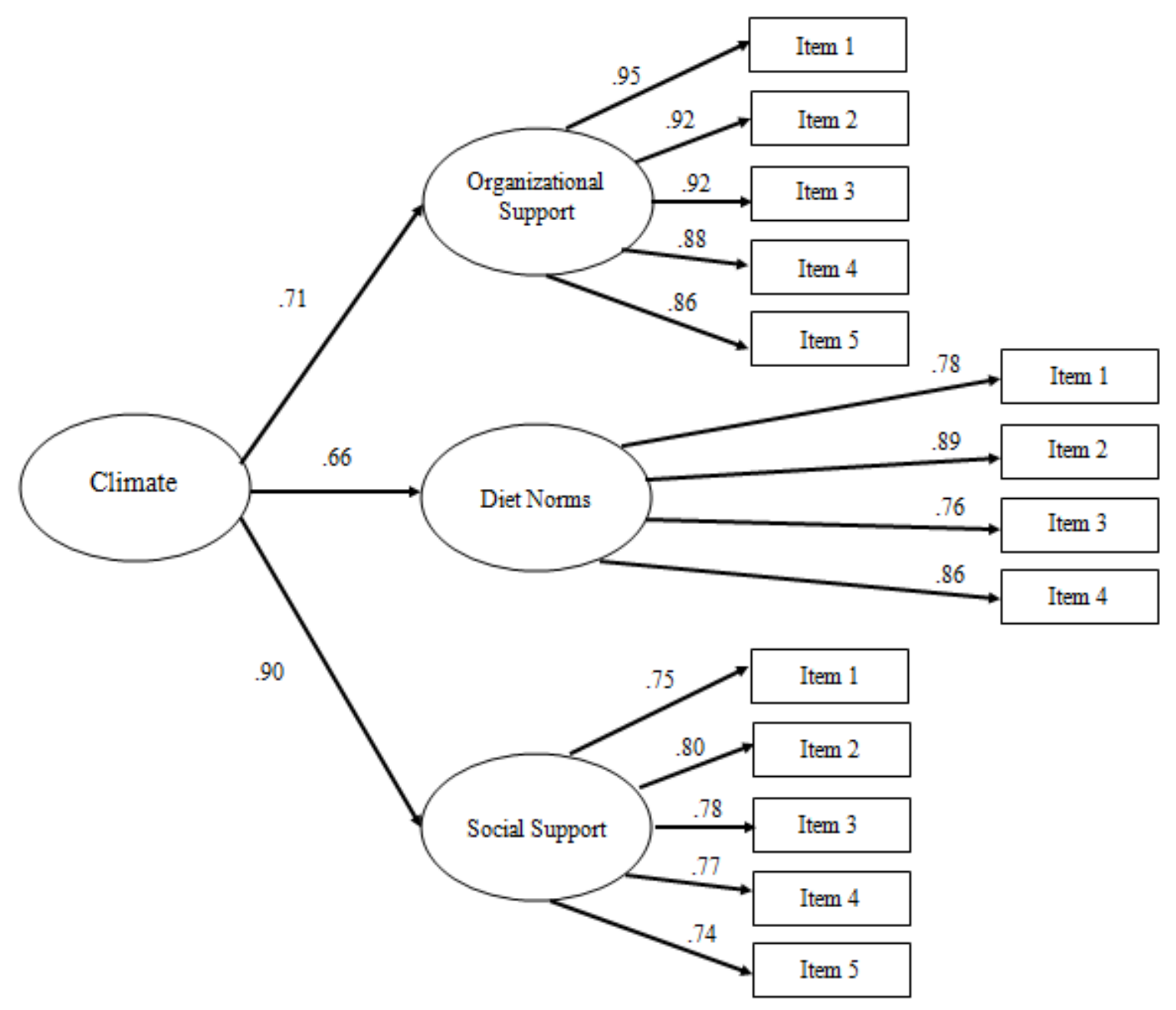




\section{APPENDIX A: MEASURES}

(Only scales developed by the author are included)

Demographic Information

\section{Instructions}

We are interested in knowing a little bit about you, personally. The following questions ask for basic demographic information which will allow us to compare responses between unique groups (males compared to females, for instance). Please remember that this survey is anonymous. We will not be able to link your responses to your name.

Items (Response options shown after each item)

1. What is your genetic sex? Male Female

2. What is your age? Open-ended

3. With which race do you primarily identify?

$\begin{array}{lll}\text { Caucasian/white } & \text { African American } & \text { Asian/Pacific Islander } \\ \text { Hispanic/Latino } & \text { Native American } & \text { Middle Easter/West Asian } \\ \text { Multi-racial } & \text { Other } & \end{array}$

4. For how many years have you been employed by your current organization? Open-ended

5. Is your position considered management? Yes No

6. What is your height? Dropdown menus for feet and inches

7. What is your weight? Open-ended 
General Physical Activity Scale

Instructions

Please think about the past month. During that time, approximately how many days per week did you engage in each of the following types of physical activity for at least 20 consectutive minutes over the course of the day?

Items

1. Light aerobic activity (Ex: Shopping, housework, light walking)

2. Moderate aerobic activity (Ex: Brisk walking, bicycling, tennis)

3. Vigorous aerobic activity (Ex: Jogging/running, swimming laps, jumping rope)

4. Muscle-strengthening activity (Ex: Lifting weights, pilates, yoga)

Response scale (scores in parentheses)

1. Unable/not medically allowed to do this (0)

2. Did not choose to do this (0)

3. 1 day per week or less (1)

4. 2-3 days per week (2)

5. 4-5 days per week (3)

6. 6-7 days per week (4) 


\section{Diet Quality}

\section{Instructions}

Please think about the past month. We are interested in knowing a bit about your dietary habits during that period. On average, Items how often would you say you consumed each of the following types of food?

\begin{tabular}{|cll|}
\hline 1 & Whole grains & $\begin{array}{l}\text { ex: Whole grain bread, oatmeal, brown rice, } \\
\text { whole grain cereal }\end{array}$ \\
\hline 2 & Leafy green vegetables & ex: broccoli, spinach, Romaine lettuce \\
\hline 3 & $\begin{array}{l}\text { Other vegetables that are } \\
\text { NOT fried }\end{array}$ & $\begin{array}{l}\text { ex: squash, cabbage, mushrooms, peppers, } \\
\text { onions, sweet potatoes }\end{array}$ \\
\hline 4 & $\begin{array}{l}\text { Fresh/canned/frozen fruit } \\
\text { (no added sugar) }\end{array}$ & ex: fresh fruit, canned fruit in juice \\
\hline 5 & Low fat or fat free dairy & $\begin{array}{l}\text { ex: reduced fat cheese, 1\% or skim milk, light } \\
\text { yogurt, string cheese }\end{array}$ \\
\hline 6 & Lean proteins & ex: fish, chicken, tofu, beans, nuts, eggs \\
\hline
\end{tabular}

\begin{tabular}{|c|c|c|}
\hline 7 & Full fat dairy * & $\begin{array}{l}\text { ex: regular cheese, ice cream, } 2 \% \text { or whole milk, } \\
\text { full fat cottage cheese }\end{array}$ \\
\hline 8 & Processed/red/organ meat * & $\begin{array}{l}\text { ex: lunch meats, hot dogs, beef, liver, sausage, } \\
\text { bacon }\end{array}$ \\
\hline 9 & Salty or fried foods* & ex: chicken fingers, chips, fries, crackers \\
\hline 10 & Solid fats/spreads * & $\begin{array}{l}\text { ex: butter, margarine, mayonnaise, creamy salad } \\
\text { dressing, lard }\end{array}$ \\
\hline 11 & Candy/cake/cookies * & \\
\hline 12 & Sweetened beverages * & $\begin{array}{l}\text { ex: Sweetened tea, Kool-Aid } \mathbb{C} \text {, lemonade, non- } \\
\text { diet soda }\end{array}$ \\
\hline
\end{tabular}

*Indicates reverse coding

Response scale (scores in parentheses)

1.) Very rarely or not at all by choice (0)

5.) Once a day (4)

2.) Less than once per week (1)

3.) 1-3 times per WEEK (2)

4.) 4-6 times per WEEK (3)

6.) 2-4 times per DAY (5)

7.) 5+ times per DAY (6)

8.) Did not or could not eat due to dietary or religious/ethical restrictions (unscored) 


\section{Climate for Healthy Weight Maintenance}

Instructions

Please think about the organization for which you currently work, as well as the people with whom you currently work. Below, you will see a series of statements that may or may not accurately describe your organization and your coworkers. Please indicate how strongly you agree or disagree with each of the following statements.

Items Key: - = Reverse coded $\quad G=$ General social support $\quad N=$ Diet norms $\quad S=$ Social support

1. My organization actively promotes maintenance of a healthy weight. (G)

2. My organization does more to promote healthy weight than other organizations I know. $(G)$

3. My organization truly cares about helping individuals stay fit and healthy. $(G)$

4. My organization provides information about how maintenance of a healthy weight is beneficial. $(\mathrm{G})$

5. Managers in my organization seem to really value employee health and fitness. (G)

6. My coworkers often encourage unhealthy food choices. $(\mathrm{N}-)$

7. It is common for my coworkers to have candy or other little treats available. ( $\mathrm{N}_{-}$)

8. When my coworkers bring food to the workplace, it tends to be sugary or fattening. ( $\mathrm{N}_{-}$)

9. My coworkers do not usually snack while working. (N)

10. My coworkers discuss ways to maintain a healthy weight. (S)

11. Most of my coworkers are actively trying to maintain a healthy weight. (S)

12. My coworkers are more committed to maintaining a healthy weight than people I know in other organizations. (S)

13. If I started a new weight loss program, I know I could count on my coworkers for support. (S)

14. My coworkers recognize one another for reaching and maintaining weight goals. (S)

Response scale (scores in parentheses)

1. Strongly disagree (1)

2. Disagree (2)

3. Neutral/neither (3)

4. Agree (4)

5. Strongly agree (5) 
APPENDIX B: HSRB APPROVAL

(Following page) 
HSRB MEMBERSHIP 2010-2011

Amy Morgan, HSRB Chair Kinesiology

amorgan@bgsu.edu

Mary Hare, HSRB Vice Chair Psychology

mlhare@bgsu.edu

D. Wayne Bell, M.D. Wood Health Corp. 353-6225

speakingdoc@dacor.net

Cheryl Conley

Alzheimer's Assn., NW Ohio conleyc@bgsu.edu

L. Fleming Fallon, Jr., M.D. Public \& Allied Health ffallon@bgsu.edu

Rodney Gabel

Comm. Sciences \& Disorders rgabel@bgsu.edu

Hillary Harms Office of Research Compliance hsrb@bgsu.edu

Lesa Lockford Theatre \& Film lockflo@bgsu.edu

Montana Miller Popular Culture montanm@bgsu.edu

Jeanne Novak Intervention Services jnovak@bgsu.edu

Ashutosh Sohoni

Family and Consumer Sciences assohon@bgsu.edu
July 26, 2012

TO: $\quad$ Katherine Wolford

Psychology

FROM: Hillary Harms, Ph.D. HSRB Administrator

RE: HSRB Project No.: H11D262GFB

TITLE: $\quad$ Developing a Method to Assess Organizational Climate for Healthy Weight

You have met the conditions for approval for your project involving human subjects. As of October 14, 2011, your project has been granted final approval by the Human Subjects Review Board (HSRB). This approval expires on June 7, 2012. You may proceed with subject recruitment and data collection.

The final approved version of the consent document(s) is attached. Consistent with federal OHRP guidance to IRBs, the consent document(s) bearing the HSRB approval/expiration date stamp is the only valid version and you must use copies of the date-stamped document(s) in obtaining consent from research subjects.

You are responsible to conduct the study as approved by the HSRB and to use only approved forms. If you seek to make any changes in your project activities or procedures, send a request for modifications to the HSRB via this office. Those changes must be approved by the HSRB prior to their implementation.

You have been approved to enroll 900 participants. If you want to enroll additional participants you must seek approval from the HSRB.

Good luck with your work. Let me know if this office or the HSRB can be of assistance as your project proceeds.

\section{Comments/ Modifications:}

Reviewer Comment: Your requirement of US citizenship is ok but is likely to introduce bias that you may not want. An alternative would be "Legally eligible to work in the US."

Please add text equivalent to the HSRB approval/expiration date stamp to the "footer" area of the electronic consent form.

c: Dr. Mike Zickar

Research Category: FULL BOARD REVIEW 